Article

\title{
Structural Similarity with Cholesterol Reveals Crucial Insights into Mechanisms Sustaining the Immunomodulatory Activity of the Mycotoxin Alternariol
}

\author{
Giorgia Del Favero ${ }^{1,2, *}{ }^{4}$, Raphaela M. Mayer ${ }^{1}$, Luca Dellafiora ${ }^{3} \oplus$, Lukas Janker ${ }^{4} \oplus$, \\ Laura Niederstaetter ${ }^{4}$, Chiara Dall'Asta ${ }^{3}$, Christopher Gerner 2,4,5,*(D) and Doris Marko 1,2 \\ 1 Department of Food Chemistry and Toxicology, Faculty of Chemistry, University of Vienna Währinger Straße \\ 38-40, 1090 Vienna, Austria; mayer.m.raphaela@gmail.com (R.M.M.); doris.marko@univie.ac.at (D.M.) \\ 2 Core Facility Multimodal Imaging Faculty of Chemistry, University of Vienna Währinger Straße 38-40, \\ 1090 Vienna, Austria \\ 3 Department of Food and Drugs, University of Parma, 43121 Parma, Italy; luca.dellafiora@unipr.it (L.D.); \\ chiara.dallasta@unipr.it (C.D.) \\ 4 Department of Analytical Chemistry, Faculty of Chemistry, University of Vienna, Währinger Straße 38, \\ 1090 Vienna, Austria; lukas.janker@univie.ac.at (L.J.); laura.niederstaetter@univie.ac.at (L.N.) \\ 5 Joint Metabolome Facility, Faculty of Chemistry, University of Vienna. Währinger Straße 38-40, \\ 1090 Vienna, Austria \\ * Correspondence: giorgia.del.favero@univie.ac.at (G.D.F.); christopher.gerner@univie.ac.at (C.G.)
}

Received: 21 February 2020; Accepted: 25 March 2020; Published: 31 March 2020

Abstract: The proliferation of molds in domestic environments can lead to uncontrolled continuous exposure to mycotoxins. Even if not immediately symptomatic, this may result in chronic effects, such as, for instance, immunosuppression or allergenic promotion. Alternariol $(\mathrm{AOH})$ is one of the most abundant mycotoxins produced by Alternaria alternata fungi, proliferating among others in fridges, as well as in humid walls. $\mathrm{AOH}$ was previously reported to have immunomodulatory potential. However, molecular mechanisms sustaining this effect remained elusive. In differentiated THP-1 macrophages, AOH hardly altered the secretion of pro-inflammatory mediators when co-incubated with lipopolysaccharide (LPS), opening up the possibility that the immunosuppressive potential of the toxin could be related to an alteration of a downstream pro-inflammatory signaling cascade. Intriguingly, the mycotoxin affected the membrane fluidity in macrophages and it synergistically reacted with the cholesterol binding agent $\mathrm{M} \beta \mathrm{CD}$. In silico modelling revealed the potential of the mycotoxin to intercalate in cholesterol-rich membrane domains, like caveolae, and immunofluorescence showed the modified interplay of caveolin- 1 with Toll-like Receptor (TLR) 4. In conclusion, we identified the structural similarity with cholesterol as one of the key determinants of the immunomodulatory potential of $\mathrm{AOH}$.

Keywords: immunomodulation; alternariol; membrane; cholesterol

\section{Introduction}

Awareness regarding the risk associated with exposure to environmental contaminants is often very limited, especially when exposure occurs inconspicuously in a domestic environment and the health consequences are spread over a broad timeframe. Increasing proof of evidence indicates a correlation between residential mold exposures with health effects on the respiratory tract [1], and mycotoxins are suspected to play a major role in immune-related diseases like asthma [2]. Other studies underpin the immunomodulatory potential of several fungal compounds [3-8]. Hence, there is an urgent need to 
better understand the molecular mechanisms mediating these effects for proper toxicological evaluation and eventually, therapeutic treatment. Alternaria alternata is a typical species identified in domestic environments [9] and it is known to produce hundreds of different secondary metabolites, many of them already classified as mycotoxins [10]. Among the most studied secondary metabolites produced by Alternaria alternata is the dibenzopyrone alternariol (AOH, Figure 1A). In our study, we decided to focus on relatively low concentrations $(0.1-1 \mu \mathrm{M})$, with the idea of trying to isolate potential effects of non-toxic dose-exposure. In commercial products, $\mathrm{AOH}$ can be found in concentrations up to $20 \mathrm{ng} / \mathrm{g}$ [11]. When administered orally to rats, $\mathrm{AOH}$ can be detected in urine and feces [10], suggesting the potential for systemic bioavailability. The immunomodulatory potential of the compound has already been described, reporting the pro-inflammatory effects on skin cells [12] and induction of senescence and cell cycle arrest in RAW264.7 mouse macrophages $[5,13,14]$. Immunosuppressive potential was also related to the capability to suppress LPS-induced activation of macrophages [3,6,7] as well as to modify cytokines transcription and release in intestinal Caco-2 cells [15]. However, key molecular mechanisms determining these responses are still under debate. Receptor-activated signaling (i.e., Toll-like receptor 4, TLR4) plays a central role in sustaining LPS-induced inflammatory cascades and such activity is highly dependent on receptor functionality, as well as on a sophisticated structural organization within the cell membrane [16]. Membrane composition (i.e., rafts and caveolae) can be crucial for receptor distribution and turnover [17]. In addition, mechanisms regulating immune responses are subject to intensive research, since acute and chronic pathologies involving the regulation of the immune system are continuously increasing [18]. In line with this, immunomodulatory action can derive, for instance, from the interaction with receptors [19], or from the modulation of the structure/biophysical properties of the surrounding environment [20]. It was recently demonstrated that membrane oxidation can interfere with pro-inflammatory signals triggered by LPS [21]. Lipid composition and the oxidation status can tune the down-streaming cascade of LPS, inducing pro-inflammatory responses [22]. Similarly, toxicants can exert their effect through direct interaction with the pro/anti-inflammatory cascade or indirectly via the modulation of cell biophysical properties. In line with this, the characterization of molecular mechanisms is central, in order to suggest proper therapeutic approaches and supportive interventions.

A
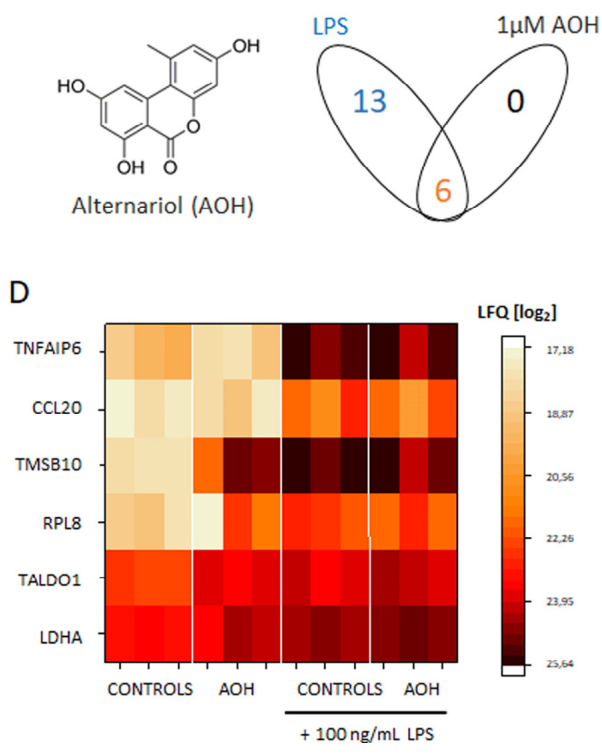

B

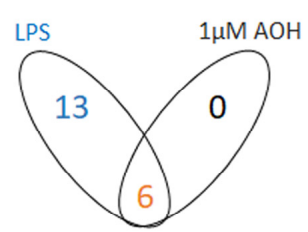

C

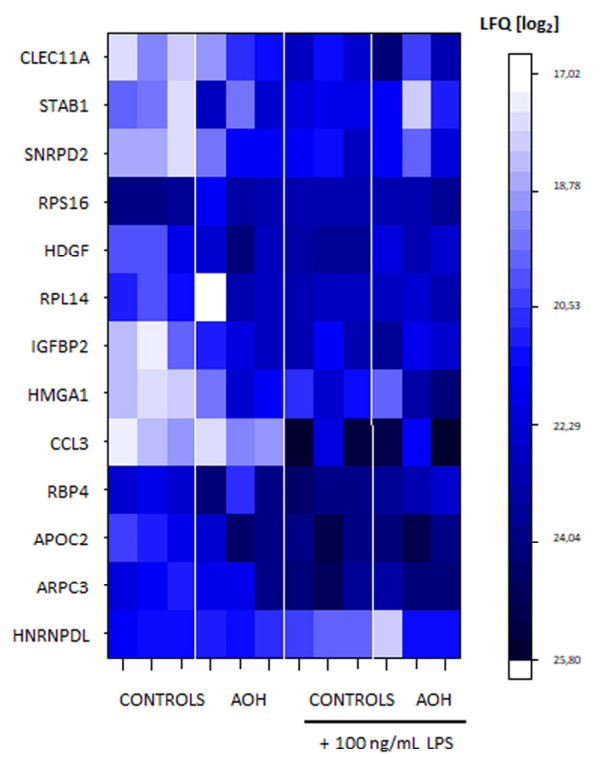

Figure 1. (A) Structure of alternariol AOH. (B) Significantly regulated proteins in the secretome of THP-1 macrophages, after $5 \mathrm{~h}$ incubation with $100 \mathrm{ng} / \mathrm{mL}$ LPS, $1 \mu \mathrm{M}$ AOH or combination of the two. (C) Thirteen proteins regulated exclusively by incubation with $100 \mathrm{ng} / \mathrm{mL}$ LPS. (D) Six proteins regulated by co-incubation with $100 \mathrm{ng} / \mathrm{mL}$ LPS and $1 \mu \mathrm{M}$ AOH. The heat map depicts the three biological replicates performed for each treatment group. 
Taking this as a starting point, we investigated the possibility that the immunomodulatory action of $\mathrm{AOH}$ could be already initiated at the membrane level. To this aim, we used the THP-1 human monocytic leukemia cell line, which can be differentiated into macrophages [6,23]. The THP-1 cells have been extensively used to study monocytes/macrophages' functions and signaling pathways, and are an established model for the study of the immunomodulatory cascades in vitro [24]. We combined secretome analysis (proteomic and eicosanoid profiling) with live cell imaging/image analysis workflows and in silico modelling in order to study the effects of the toxin at membrane level. Indeed, thanks to this approach, we were able to relate $\mathrm{AOH}$ structural similarity with cholesterol as a key determinant of its immunomodulatory potential.

\section{Materials and Methods}

\subsection{Cell Culture Conditions and Reagents}

THP-1 monocytes were purchased from (ATCC ${ }^{\circledR}$ TIB202 ${ }^{\mathrm{TM}}$ ) and kept in culture in RPMI 1640 Medium supplemented $10 \% \quad v / v$ heat-inactivated fetal calf serum (FCS) and $1 \% \quad v / v$ penicillin/streptomycin $(\mathrm{P} / \mathrm{S})$. Macrophage differentiation was induced through incubation with phorbol-12-myristate-13-acetate (PMA, $10 \mathrm{ng} / \mathrm{mL}$ ) for $72 \mathrm{~h}$, followed by an additional $24 \mathrm{~h}$ in PMA free medium, as previously described [6,23]. LPS stimulation $100 \mathrm{ng} / \mathrm{mL}$ and solvent controls (controls) DMSO $0.1 \%$.

\subsection{Supernatant Analysis of Eicosanoids and Proteomics}

The cells were seeded in a T25 cell culture flask at $80 \%$ confluence with the complete medium. After $3 \mathrm{~h}$ incubation the supernatant was removed, spiked with 10-100 nM of each internal standard, centrifuged with $726 \times g$ and $3 \mathrm{~mL}$ precipitated with $12 \mathrm{~mL}$ ethanol (EtOH, abs. 99\%; AustroAlco), and stored at $-20{ }^{\circ} \mathrm{C}$ over night. Precipitated proteins were eliminated, and the eicosanoids were further processed from the supernatants. The cells were washed twice with Phosphate Buffer Saline (PBS) and cells were incubated with serum-free medium, containing the stimuli of interest. After additional $2 \mathrm{~h}$ incubation the supernatant was removed, centrifuged, and precipitated in ethanol overnight to obtain the secreted proteins.

\subsection{Protein Sample Preparation}

The proteins were used for a filter-assisted protein digest, as described previously [25]. Briefly, the isolated proteins were centrifuged at $4536 \times \mathrm{g}$ for $30 \mathrm{~min}$ and the protein pellet dried. After dissolving in sample buffer, the protein concentration was determined with a Bradford assay and $20 \mu \mathrm{g}$ of total protein was used for the digestion. After reduction with dithiothreitol and alkylation with iodacetamid (both Sigma-Aldrich, Vienna, Austria), proteins were digested with Trypsin/Lys-C (MS grade; Promega Corporation, Madison, WI, USA) and dried via vacuum centrifugation.

\subsection{Lipids Sample Preparation}

Samples were centrifuged ( $30 \mathrm{~min}, 4536 \times g, 4{ }^{\circ} \mathrm{C}$ ) and the supernatant was transferred to new $15 \mathrm{~mL}$ Falcon tubes. Ethanol was eliminated via SpeedVac $\left(37^{\circ} \mathrm{C}\right)$, until the original sample volume was restored. Samples were loaded on conditioned $30 \mathrm{mg} / \mathrm{mL}$ StrataX solid phase extraction (SPE) columns (Phenomenex, Torrance, CA, USA) Columns were washed with $2 \mathrm{~mL}$ MS grade water and eicosanoids were eluted with $500 \mu \mathrm{L}$ methanol (MeOH abs.; VWR International, Vienna, Austria) containing 2\% formic acid (FA; Sigma-Aldrich). $\mathrm{MeOH}$ was evaporated using $\mathrm{N}_{2}$ stream at room temperature and reconstituted in $150 \mu \mathrm{L}$ reconstitution buffer $\left(\mathrm{H}_{2} \mathrm{O} / \mathrm{ACN} / \mathrm{MeOH}+0.2 \% \mathrm{FA} \mathrm{-} \mathrm{65:31,5:3,5),} \mathrm{containing} \mathrm{a}\right.$ set of internal eicosanoid standards at a concentration of 10-100 nM. 


\subsection{Membrane Fluidity}

Membrane fluidity was measured as previously described [23], with slight modifications. Differentiated THP-1 cells were incubated for $1 \mathrm{~h}$ at $37^{\circ} \mathrm{C}$ with $10 \mu \mathrm{M}$ 1-pyrenedecanoic acid (PDA), diluted in live cell imaging solution. After challenge with the stimuli of interest, fluorescence was measured with a Cytation ${ }^{\mathrm{TM}} 3$ Cell Imaging Multi-Mode Reader equipped with the Gen $5^{\mathrm{TM}}$ Data Analysis Software (BioTek Instruments, Inc., Winooski, VT, USA). The signal was expressed as a ratio between ex/em. 344/470 nm for the PDA excimers, and ex/em. 344/375 for the monomeric form. Data are the mean of eight independent experiments, performed in quadruplicates.

\subsection{Live Cell Imaging: Membrane Morphology}

For membrane visualization, THP-1 macrophages were incubated with with CellMask ${ }^{\mathrm{TM}}$ Deep Red Plasma Membrane Stain for 15 min (1:1000 dilution, depicted in white). Staining solution was diluted in Live Cell Imaging Solution (all reagents were purchased by Molecular Probes, Life Technologies, Thermo Fisher Scientific, Waltham, MA, USA). At the end of the staining, cells were rinsed and maintained in Live Cell Imaging Solution for the microscopy analysis.

\subsection{Live Cell Imaging: Mitochondrial Superoxide}

For superoxide quantification, cells were incubated for 15 min with MitoTracker ${ }^{\circledR}$ Green FM (1:1000 dilution, depicted in blue, indicated as MitoTracker), and MitoSOX ${ }^{\mathrm{TM}}$ Red mitochondrial superoxide indicator (1:1000 dilution, red to white, indicated as MitoSOX), as previously described [24]. All reagents were purchased by Molecular Probes, Life Technologies, Thermo Fisher Scientific, Waltham, MA, USA. For the evaluation of the signal intensity, regions of interest (ROI) were selected using the MitoTracker signal as reference, and data were expressed as MitoSox/MitoTracker ratio. Staining solutions were diluted in Live Cell Imaging Solution. At the end of the staining, cells were rinsed and maintained in Live Cell Imaging Solution for the microscopy analysis.

\subsection{Immunofluorescence}

For immunofluorescence experiments [23,26], cells were processed as previously described, with slight modifications $[23,26]$. Briefly, THP- 1 macrophages were incubated for $1 \mathrm{~h}$ and immediately fixed with pre-warmed 3.7\% formaldehyde (15 min, room temperature). After permeabilization $(0.2 \%$ Triton-X-100, $10 \mathrm{~min}$ ), unspecific binding sites were blocked ( $2 \%$ Donkey Serum, $0.5 \%$ Bovine Serum Albumine, $1 \mathrm{~h}$ ). Afterwards, cells were incubated for $2 \mathrm{~h}$ with anti-Caveolin-1 antibody (Abcam, ab192452, 1:500), anti-TLR4 antibody [76B357.1] (Abcam, ab22048, 1:200) and anti MIF antibody (Abcam, ab7207, 1:500). After 5 washing steps, species-specific fluorescence-labeled antibodies were used for localization (Donkey Anti-Goat IgG (H+L), Alexa Fluor ${ }^{\circledR} 647$ (705-605-003) and Donkey Anti-Mouse IgG (H+L) Alexa Fluor ${ }^{\circledR} 488$ (715-545-150) from Jackson ImmunoResearch Laboratories, Inc., Pennsylvania, US and Donkey anti-Rabbit IgG $(\mathrm{H}+\mathrm{L})$ polyclonal secondary antibody, Alexa Fluor $^{\circledR} 568$ (A10042) from Thermo Fisher Scientific, Waltham, US).

\subsection{Microscopy}

Images were acquired with a Zeiss LSM 710 Confocal Microscope with a ELYRA PS.1 system, for super-resolution with a Plan-Apochromat $63 \mathrm{x} / 1.2$ water objective for live cell imaging and a Plan Apochromat 63X/1.4 oil objective for the immunofluorescence experiments. Images were analyzed with the software ZEN Zeiss. If not otherwise specified, optical fields/region of interest (ROI) were quantified for every experimental setup, from at least 3-4 independent experiments.

\subsection{Statistical Analysis}

Data were evaluated with the software OriginPro 2018b (OriginLab Corporation, Northampton, MA, USA). Multiple comparisons of independent samples were performed with a one-way ANOVA 
test followed by a Fisher test. Student's $t$-tests were applied for the direct comparison of groups of data. Distributions were considered different, using threshold values of 0.05 .

\subsection{Data Analysis Secretome}

For the HPLC-MS/MS analysis, the peptides were resolved in $5 \mu \mathrm{L} \mathrm{30 \%} \mathrm{formic} \mathrm{acid} \mathrm{and} \mathrm{diluted} \mathrm{with}$ $40 \mu \mathrm{L}$ of mobile phase $\mathrm{A}\left(97.9 \% \mathrm{H}_{2} \mathrm{O}, 2 \%\right.$ acetonitrile, $0.1 \%$ formic acid). Then, $1 \mu \mathrm{L}$ for the supernatant samples and $10 \mu \mathrm{L}$ of cytoplasmic and nuclear samples were injected into the Dionex UltiMate 3000 RSLCnano LC system, coupled to the QExactive Orbitrap MS (all Thermo Fisher Scientific, Vienna, Austria). Peptides were trapped on a C18 $2 \mathrm{~cm} \times 100 \mu \mathrm{m}$ precolumn, and LC separation was performed on a $50 \mathrm{~cm} \times 75 \mu \mathrm{m}$ Pepmap100 analytical column (both Thermo Fisher Scientific, Austria). Following this, $1 \mu \mathrm{L}$ of sample was injected. The $85 \mathrm{~min}$ HPLC method included a $43 \mathrm{~min}$ gradient from $7 \%$ to $40 \%$ mobile phase $\mathrm{B}\left(79.9 \%\right.$ acetonitrile, $20 \% \mathrm{H}_{2} \mathrm{O}, 0.1 \%$ formic acid) at a flow rate of $300 \mathrm{~nL} / \mathrm{min}$. The resolution on the MS1 level was set to 70,000 (at $m / z=200$ ), with a scan range from 400 to $1400 \mathrm{~m} / \mathrm{z}$. The top eight abundant peptide ions were chosen for fragmentation at 30\% normalized collision energy and resulting fragments were analyzed in the Orbitrap at a resolution of $17,500($ at $m / z=200)$.

\subsection{Proteomics Data Analysis}

Raw data were subjected to the freely available software MaxQuant (version 1.6.0.1), utilizing the Andromeda search engine, followed by statistical evaluation with the Perseus software (version 1.6.0.2) [27-31]. For the MaxQuant search, a minimum of two peptide identifications, at least one of them being a unique peptide, was required for valid protein identification. Digestion mode was set to "Specific", choosing Trypsin/P. The peptide mass tolerance was set to 50 ppm for the first search and to $25 \mathrm{ppm}$ for the main search. The false discovery rate (FDR) was set to 0.01, both on peptide and protein levels, based on the q-value. The database applied for the search was the human Uniprot database (version 03/2018, reviewed entries only), with 20,316 protein entries. Further settings for the search included carbamidomethylation as fixed modification and oxidation of methionine and acetylation of the protein $C$ terminus as variable modifications. (Principal Component Analysis, PCA) is provided in Supplementary Figure S1.

\subsection{UHPLC-MS/MS for Eicosanoid Measurements}

Analytes were separated using a Thermo Scientific Vanquish (UHPLC) system and a Kinetex ${ }^{\circledR}$ C18 — column $\left(2.6 \mu \mathrm{m}\right.$ C18 $100 \AA$ A, LC Column $150 \times 2.1$ mm; Phenomenex $\left.{ }^{\circledR}\right)$. A 20 min gradient flow method was applied, starting at 35\% B and steadily increasing to $90 \%$ B (1-10min), going up to $99 \%$ B in $0.25 \mathrm{~min}$. Flow rate was kept at $200 \mu \mathrm{L} / \mathrm{min} ; 20 \mu \mathrm{L}$ injection volume and column oven temperature was set to $40{ }^{\circ} \mathrm{C}$. Eluent A contains $\mathrm{H}_{2} \mathrm{O}+0.2 \%$ FA and eluent B ACN:MeOH (90:10) + 0.2\% FA

A mass spectrometric analysis was performed, with a Q Exactive HF Quadrupole-Orbitrap mass spectrometer (Thermo Fisher Scientific, Austria), equipped with a HESI source (heated electrospray ionization) for negative ionization. Mass spectra were recorded, operating from 250 to $700 \mathrm{~m} / \mathrm{z}$ at a resolution of $60,000 @ 200 \mathrm{~m} / z$ on MS1 level. The two most abundant precursor ions were selected for fragmentation (HCD 24 normalized collision energy), preferentially molecules from an inclusion list, which contained $32 \mathrm{~m} / z$ values specific for eicosanoids. MS2 was operated at a resolution of 15,000 at $200 \mathrm{~m} / \mathrm{z}$. For negative ionization, a spray voltage of $2.2 \mathrm{kV}$ and a capillary temperature of $253^{\circ} \mathrm{C}$ were applied, with the sheath gas set to 46 and the auxiliary gas to 10 arbitrary units.

Raw files generated by the Q-ExactiveTM OrbitrapTM were analyzed manually, using Thermo Xcalibur 4.1.31.9 (Qual browser), referring to lipid standards for all described lipids purchased from Cayman (Cayman Europe, Tallinn, Estonia). For peak integration, the software TraceFinderTM (version 4.1-Thermo Scientific, Austria) was used. 


\subsection{In Silico Molecular Modeling}

The molecular modeling approach relied on an integrated use of docking, pharmacophore modeling and molecular dynamic (MD) simulations.

Both the 3D structures of $\mathrm{AOH}$ and cholesterol were downloaded from the PubChem database (https://pubchem.ncbi.nlm.nih.gov/). Conversely, the caveolin scaffolding domain (CSD) region still lacks a through 3D characterization. Therefore, the portion 86-KASFTTFTVTKYWFYRL-102, which is thought to include the CRAC motif (cholesterol recognition-interaction amino acid consensus), was modeled in silico using the Build Protein module of the software Sybyl v. 8.1 (www.certara.com). Albeit, a consensus on the secondary structure of this region is still missing, the alpha-helix conformation was chosen in agreement with: (i) previous studies addressing the modeling of CRAC domains [32,33]; (ii) evidences pointing to the from- $\beta$ sheet-to- $\alpha$ helix shift getting close to the central residues of the CRAC motif [17]; (iii) muclear magnetic resonance data highlighting the predominant alpha-helical structure of CRAC [34]; (iv) the sheet-helix transitions observed in CRAC motifs, adjacent to trans-membrane helices [35].

Pharmacophoric analysis. The modeling of pharmacophoric space was done using the GRID module algorithm, implemented in the software Flap (Fingerprint for Ligand And Protein; https://www.moldiscovery.com) [36]. This step aimed at describing, in terms of polar and hydrophobic repartition, the surrounding space available for arranging ligands.

Docking study. The docking study aimed at assessing the mode of binding of at the CRAC domain, in comparison to that of cholesterol, taken as reference. The GOLD software [37] was used to perform all the docking simulations. The software setting parameters and docking procedures reported by Dellafiora and co-workers were used [38].

MD simulations. The best scored pose of $\mathrm{AOH}$ underwent $\mathrm{MD}$ simulations over $50 \mathrm{nsec}$ to assess the capability of $\mathrm{AOH}$ to geometrically persist at the CRAC domain during the considered timeframe. In particular, MD simulations were performed using GROMACS (version 5.1.4) [39], with CHARMM27 all-atom force field parameters support [40], in agreement with a previous study [41] Briefly, protein-peptides complexes were solvated with SPCE waters (electrochemical screen printed carbon electrodes) in a cubic periodic boundary condition, and counter ions $\left(\mathrm{Na}^{+}\right.$and $\left.\mathrm{Cl}^{-}\right)$were added to neutralize the system. Prior to MD simulation, the systems were energetically minimized to avoid steric clashes and to correct improper geometries using the steepest descent algorithm with a maximum of 5000 steps. Afterwards, all the systems underwent isothermal ( $300 \mathrm{~K}$, coupling time 2 psec) and isobaric ( 1 bar, coupling time 2 psec) 100 psec simulations, before running $50 \mathrm{nsec}$ simulations (300 K with a coupling time of $0.1 \mathrm{psec}$ and 1 bar with a coupling time of $2.0 \mathrm{psec}$ ).

\section{Results}

\subsection{Crosstalk between AOH and LPS, with Regard to the Secretome of THP-1 Macrophages}

It was previously demonstrated that $\mathrm{AOH}$ may suppress pro-inflammatory induction triggered byLPS $[3,6]$. We took advantage of untargeted proteome profiling, and investigated the effects of LPS and/or AOH on the secretome profile in THP-1 macrophages. At a sub-cytotoxic concentration $(1 \mu \mathrm{M}$, Supplementary Figure S2), AOH alone did not elicit any detectable response in the secretome profile of the macrophages (Figure 1B, $5 \mathrm{~h}$ incubation). LPS treatment resulted in the significant regulation of 19 proteins in THP-1 macrophages (Figure 1B-D). However, a combination of the two treatments (LPS and $\mathrm{AOH}$ ) reduced the number of proteins regulated by LPS to 6 (Figure 1B,D). These 6 proteins were found consistently regulated in presence or absence of $\mathrm{AOH}$, and all of them are pro-inflammatory mediators (Figure 1D). This result suggested that the macrophages could retain the capability to release pro-inflammatory mediators in response to LPS, even in the presence of $\mathrm{AOH}$ and opened the possibility that the crosstalk between the two could occur downstream from this point. 


\subsection{Effect of AOH on the Membrane of THP-1 Macrophages}

Considering the response capability of THP-1 macrophages to combined LPS and AOH stimulation, we pursued the hypothesis that $\mathrm{AOH}$ could impair signal transduction of the pro-inflammatory cascade. As the response to LPS is mediated by trans-membrane receptors [16,42] and membrane oxidative status is considered crucial for the propagation of the inflammatory cascade [21], the effects of the toxin on the membrane biophysical properties and morphology were investigated. Membrane fluidity was found to be increased in a concentration dependent fashion in the presence of the mycotoxin and this effect was counteracted by the presence of the cholesterol-complexing agent methyl-beta cyclodextrin [43] (M $\beta C D$, Figure 2A). The presence of LPS caused a general increase of membrane fluidity and possibly reduced the visibility of the competition between $\mathrm{AOH}$ and $\mathrm{M} \beta \mathrm{CD}$ (Figure 2B). Since measurement of the membrane fluidity is technically limited to a reduced incubation time (10 $\mathrm{min}$ ) [23], the morphological response of the cell membrane was also monitored (1 $\mathrm{h}$ incubation, Figure 2C,D). Appearance of the cell membrane (evaluated as intensity of the CellMask staining) was altered by incubation with $\mathrm{M} \beta C D$, but no effect could be attributed to the mycotoxin $\mathrm{AOH}$ (Figure 2C-E). In the presence of LPS, macrophages increased their spreading area, as previously also described upon activation in other models [44]. The co-incubation with $\mathrm{AOH}$ and/or M $\beta C D$ reduced this response and possibly also influenced the lipid reorganization, which is typically associated to it. This phenomenon could be followed also as a decrease of the signal of the cell membrane fluorescence tracking (Figure 2D-F).

\subsection{Effect of AOH on Mitochondrial Superoxide}

In order to verify if the effects of $\mathrm{AOH}$ on membrane fluidity could be associated to oxidative stress and reactive oxygen species (ROS) increase [23], the potential of $\mathrm{AOH}$ to induce superoxide ion production was measured via mitochondrial ROS formation. It is well known that mitochondrial ROS may impact on lipid peroxidation and consequently on membrane biophysical properties [45], as well as play a central role in inflammatory cascades $[46,47]$. In all conditions, the treatment with LPS was associated with an increase of mitochondrial superoxide, while no effect could be attributable to $\mathrm{AOH}$ alone (Figure 3). Relevance of the quantification, expressed as MitoSox/MitoTracker signal intensity ratio (Figure 3B), was confirmed by the constant signal of MitoTracker (blue, Figure 3C). Hence, differently to LPS, the effects on the lipid membrane triggered by $\mathrm{AOH}$ seemed to be independent from pathways regulating the mitochondrial superoxide production.

\subsection{Crosstalk between $A O H$ and $M \beta C D$ on the Secretome of THP-1 Macrophages}

In order to deeper investigate the cross-talk between $\mathrm{AOH}$ and $\mathrm{M} \beta \mathrm{CD}$, the analysis on the secretome of THP- 1 was extended with the respective experimental conditions. As for $1 \mu \mathrm{M} \mathrm{AOH}$, secretome analysis revealed no significantly regulated proteins in macrophages incubated with $50 \mu \mathrm{M}$ $\mathrm{M} \beta \mathrm{CD}$ (Figure 4). However, the combination of the two compounds triggered the significant regulation of more than 40 proteins (Figure 4). Among these, we identified proteins important for the metabolism and cellular structural organization like monocarboxylate transporter 4 (SLC16A3), insulin-like growth factor-binding protein 2 (IGFBP2). Moreover, the nucleoside diphosphate kinase A (NME1, involved in the phosphorylation of membrane proteins [48]) was found consistently up-regulated as well as rho GDP-dissociation inhibitor 1 (ARHGDIA). Rho GDP-dissociation inhibitor is essential for the homeostasis of Rho GTPases [49] and plays a central role in the regulation of the expression of COX-2 [50]. Same behavior could be measured for Thymosin beta-10 (TMSB10) and this can be possibly related to the morphological change of the THP-1 cells upon treatment, as previously already reported also in breast cancer cells [51]. Similarly, the release of the cytoskeletal binding protein Rootletin (CROCC) [52] also increased, whereas the charged multivesicular body protein $4 \mathrm{~b}$ (CHMP4B) was significantly down-regulated. CHMP4B belongs to the endosomal-sorting complex required for transport (ESCRT) that regulates membrane budding and exosomes formation [53] (Figure 4). Overall, 
many regulatory events seemed to have the membrane and membrane bound proteins as common denominator thus reinforcing the hypothesis that AOH could act at this level in THP-1 macrophages.
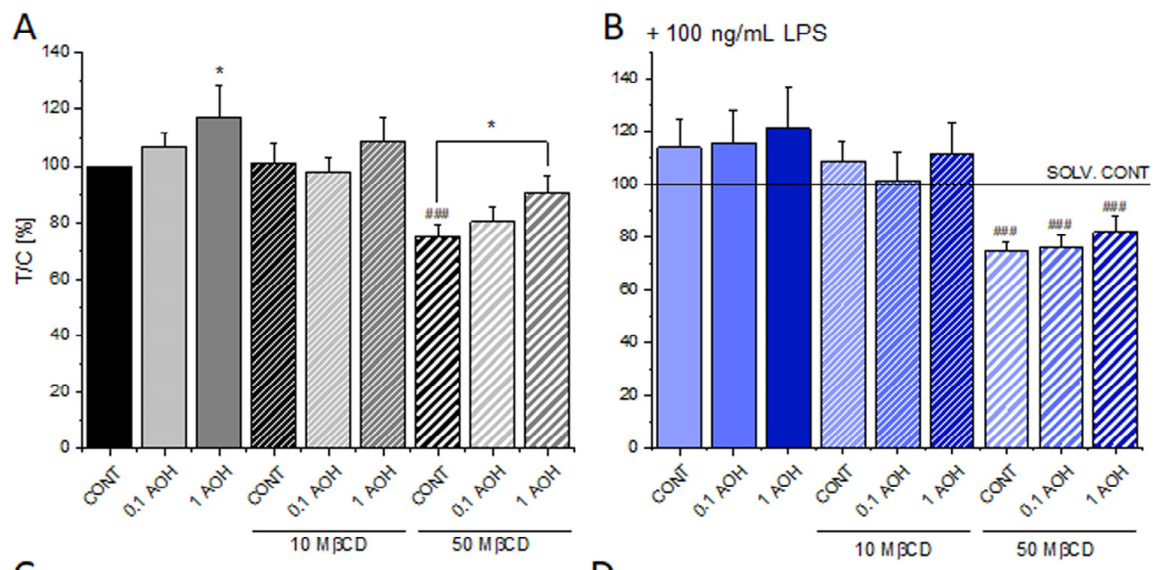

C

\section{D} $+100 \mathrm{ng} / \mathrm{mL}$ LPS

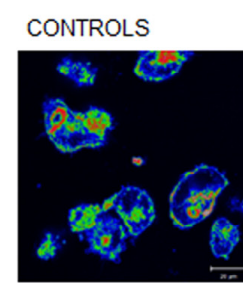

$+50 \mu \mathrm{M} \mathrm{M \beta CD}$
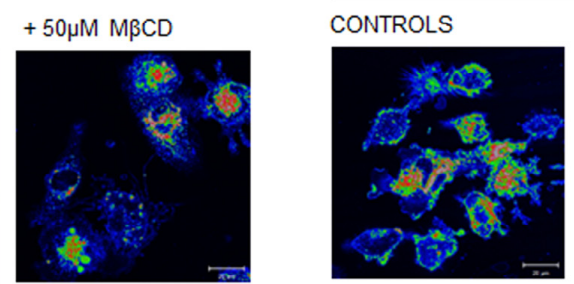

$+50 \mu \mathrm{M} \mathrm{M \beta CD}$
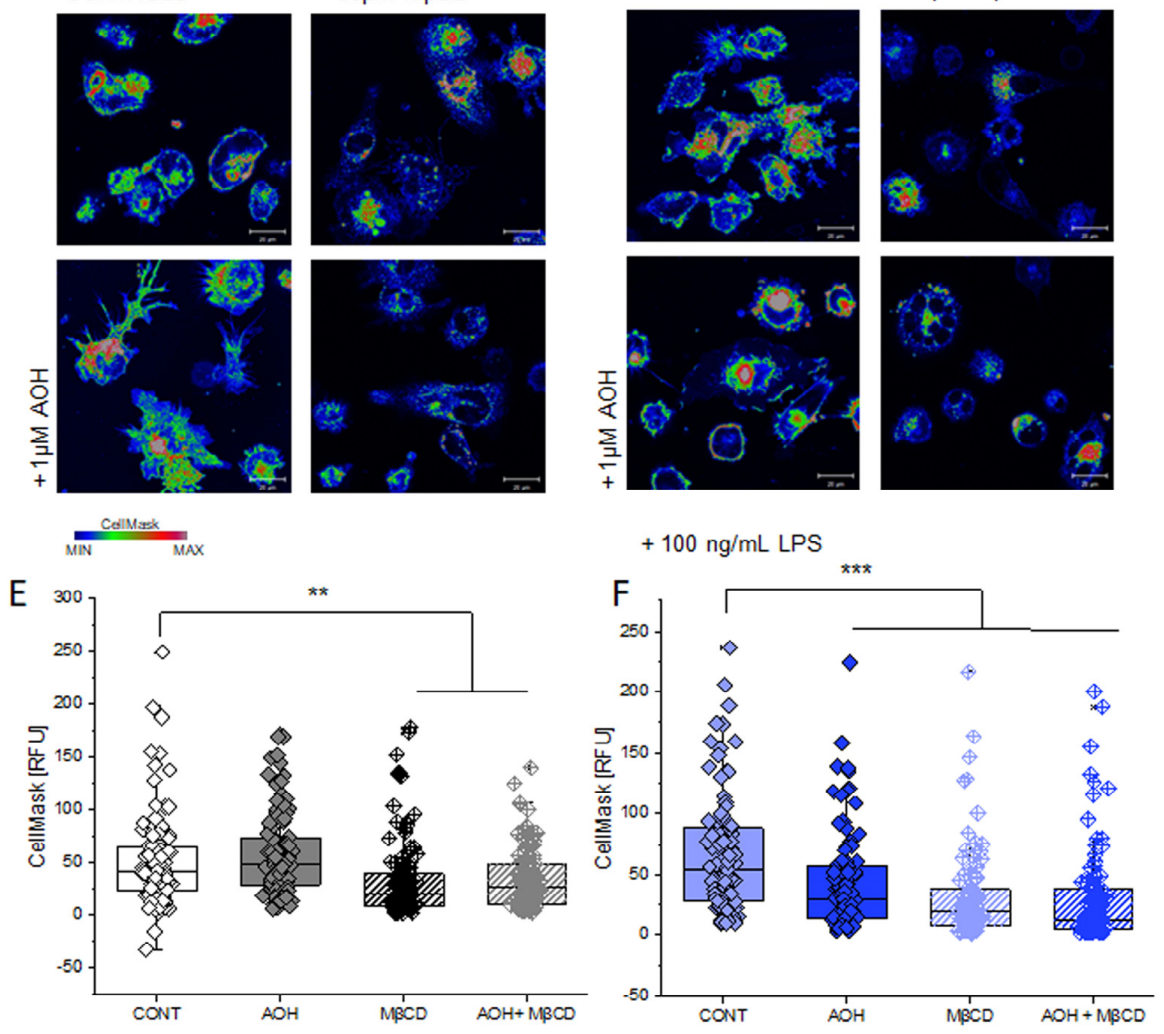

Figure 2. Effect of $\mathrm{AOH}(0.1-1 \mu \mathrm{M})$ and $\mathrm{M} \beta \mathrm{CD}(10-50 \mu \mathrm{M})$ on the membrane fluidity of THP-1 macrophages at indicated conditions (A) and in additional presence of $100 \mathrm{ng} / \mathrm{mL}$ LPS (B). Data are mean \pm SEM of eight independent experiments performed in triplicate. \#\#\# $(p<0.001)$ identifies significant decrease, according to the ANOVA test with Fisher test in comparison to controls. The appearance of the membrane of THP-1 macrophages (C,D) after $1 \mathrm{~h}$ incubation with the compounds of interest and staining with CellMask for cell membrane. Scale bar: $20 \mu \mathrm{m}$. Quantification of fluorescence intensity of the cell membrane staining (RFU, Relative Fluorescence Units; $1 \mu \mathrm{M}$ AOH, $50 \mu \mathrm{M} \mathrm{M} \beta C D$ or $1 \mu \mathrm{M} \mathrm{AOH}+50 \mu \mathrm{M} \mathrm{M} \beta C D ;(\mathbf{E}, \mathbf{F}))$. Data are obtained from the quantification of $\mathrm{n} \geq 80$ cells from four independent experiments and ${ }^{* *}$ and ${ }^{* * *}$ indicate significant difference in comparison to controls with $p<0.01$ and $p<0.001$ with Student's $t$-test. 
A

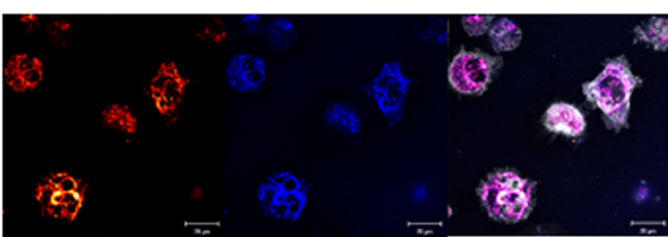

$1 \mu \mathrm{M} \mathrm{AOH}$

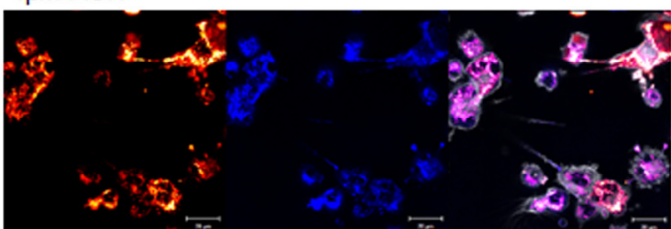

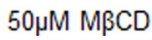

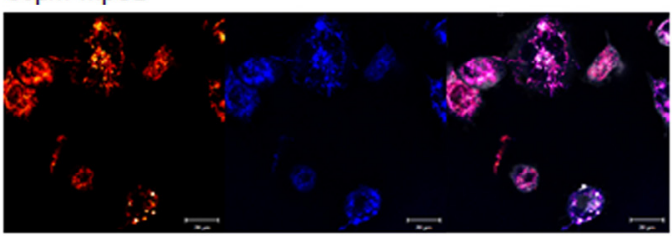

$1 \mu \mathrm{M} \mathrm{AOH}+50 \mu \mathrm{M} \mathrm{M \beta CD}$

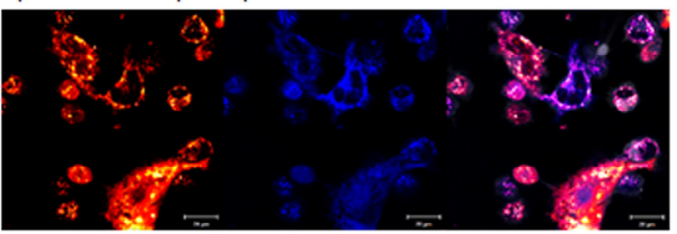

MitoSox MitoTracker

\section{B}

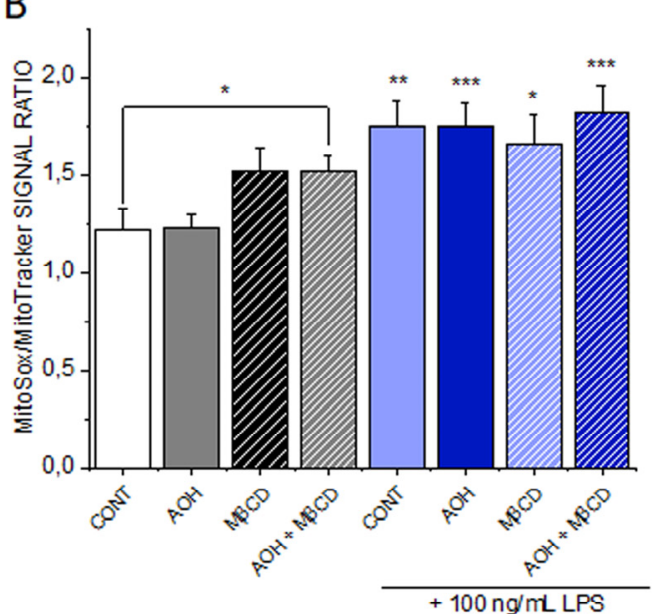

$+100 \mathrm{ng} / \mathrm{mL}$ LPS

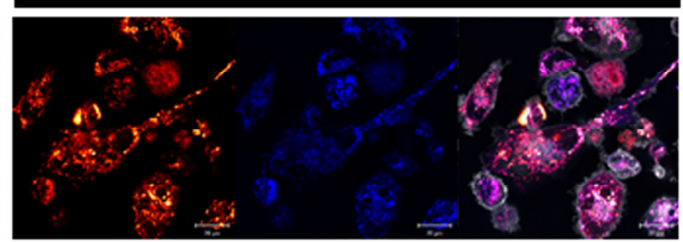

$1 \mu \mathrm{M} \mathrm{AOH}$

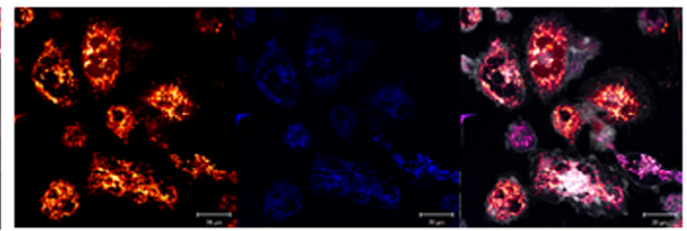

$50 \mu \mathrm{M} \mathrm{M \beta CD}$

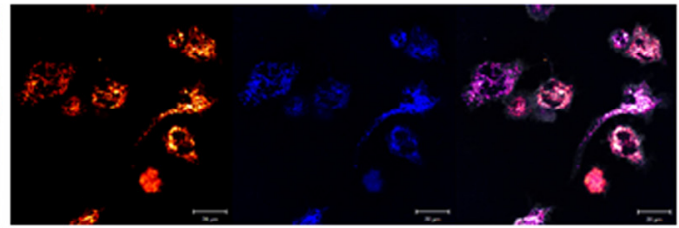

$1 \mu \mathrm{MAOH}+50 \mu \mathrm{M} M \beta C D$

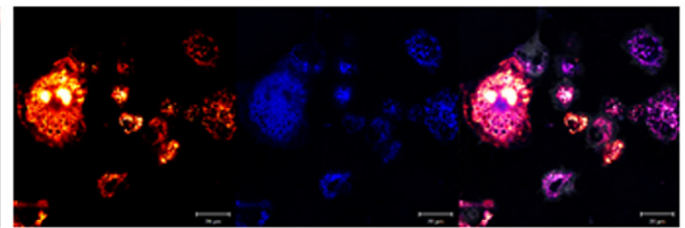

C

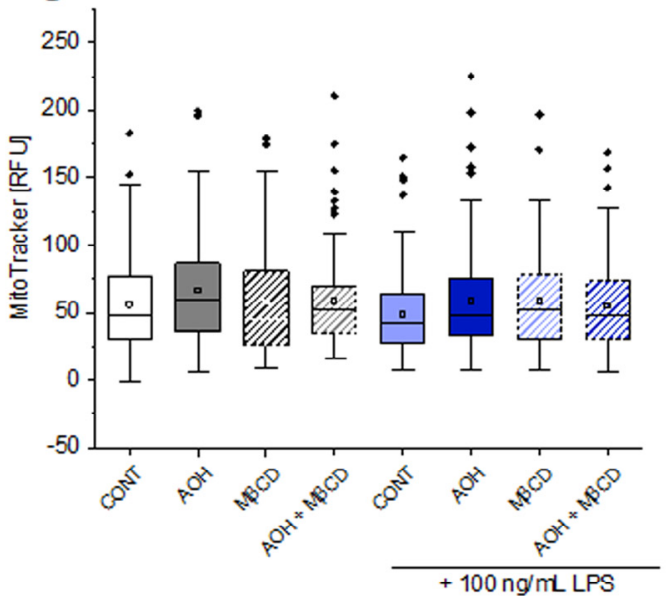

Figure 3. Mitochondrial superoxide response in THP-1 macrophages. Signal intensities of MitoSox range from orange to white, of MitoTracker from black to blue (see color bars) and cell membraneintensities are depicted in white (A). MitoSox/MitoTracker signal ratio measured after $1 \mathrm{~h}$ incubation (B). Intensity of the mitochondrial signal as reference $(\mathbf{C})$. Incubation refer to $1 \mu \mathrm{M} \mathrm{AOH}, 50 \mu \mathrm{M} \mathrm{M} \beta \mathrm{CD}$ or combination of the two in presence or absence of LPS $100 \mathrm{ng} / \mathrm{mL}$. Scale bar, $20 \mu \mathrm{m}$. Data are mean \pm SEM n $\geq 80$ cells from 4 independent experiments. ${ }^{*}(p<0.05),{ }^{* *}(p<0.01),{ }^{* * *}(p<0.001)$ significant difference according to Student's $t$-test in comparison to controls. 


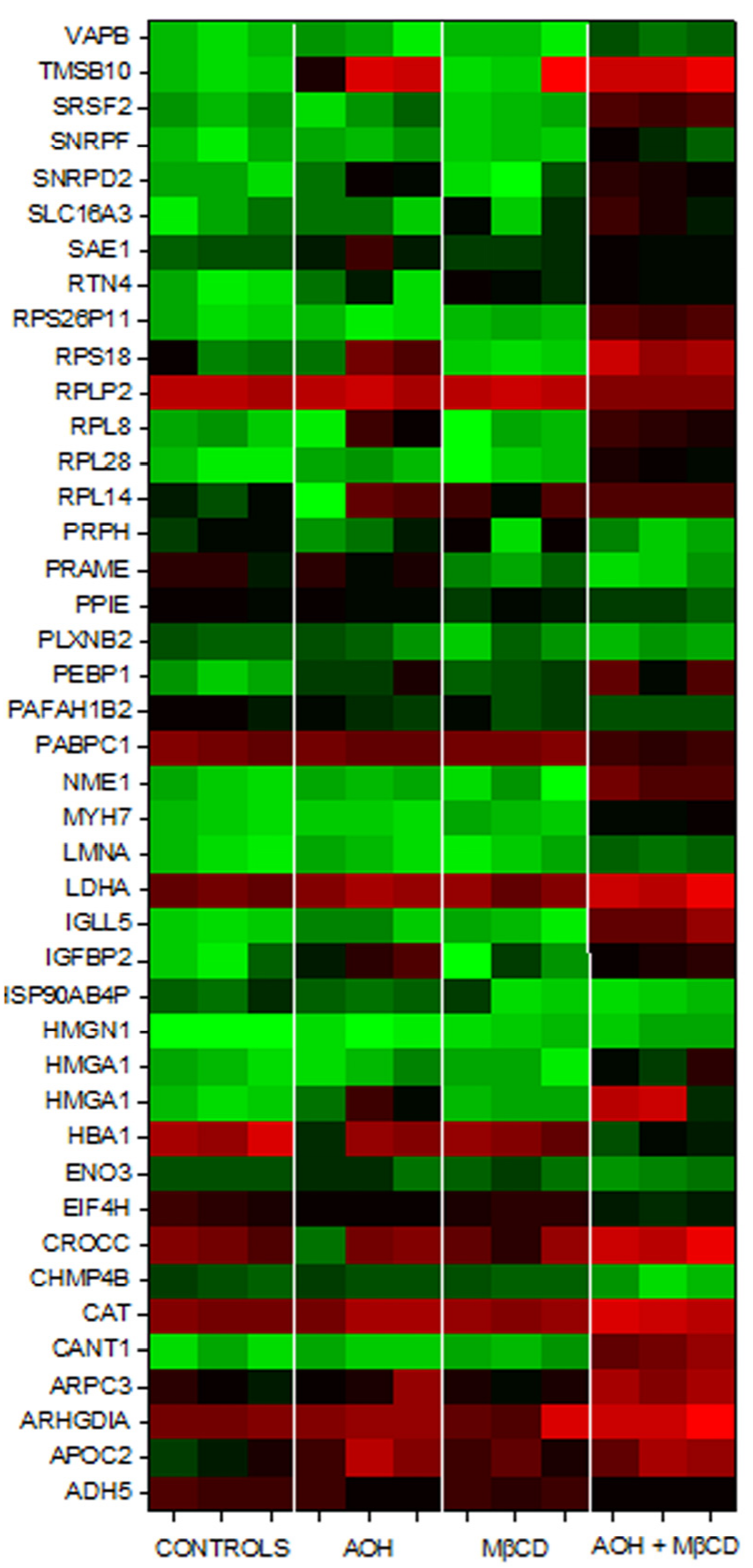

LFQ $\left[\log _{2}\right]$

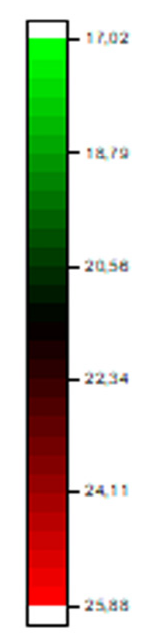

Figure 4. Secretome analysis of THP-1 macrophages incubated with $\mathrm{AOH}(1 \mu \mathrm{M})$ and/or $\mathrm{M} \beta \mathrm{CD}(50 \mu \mathrm{M})$ for $5 \mathrm{~h}$. Heat map depict the 3 biological replicates performed for each treatment group and includes all the proteins significantly regulated by the combination of $1 \mu \mathrm{M} A O H+50 \mu \mathrm{M} M \beta C D$. Single treatment $(1 \mu \mathrm{M}$ AOH or $50 \mu \mathrm{M} \mathrm{M} \beta \mathrm{CD}$ alone) induced no significant regulation in comparison to controls. Green to Red colors depict the variation of the LFQ intensities [ $\left.\log _{2}\right]$.

\subsection{Computational Study of Molecular Interactions between AOH and Cholesterol}

Since the cross-talk between $\mathrm{M} \beta \mathrm{CD}$ and $\mathrm{AOH}$ appeared to be centered at membrane level, affecting membrane biophysical properties as well as the secretome of THP-1 macrophages, we pursued the hypothesis that immunomodulatory action of the mycotoxin could be related to a direct effect with membrane structures/receptors. Since the effects of AOH on THP-1 pointed toward a competition with cholesterol, we decided to investigate the likelihood of $\mathrm{AOH}$ to interact with typical membrane structures containing cholesterol. Particularly, caveolin 1 allows the binding of cholesterol [54], and homeostasis of 
the protein is gaining more and more importance in the regulation of inflammatory processes [55-58], as well as acting as a cell mechanosensor and metabolic regulator and scaffolding domain for intracellular proteins [59-61]. In order to clarify the binding potential of $\mathrm{AOH}$, a pharmacophoric analysis of the CRAC portion of the CSD domain of caveolin 1 was performed. This approach showed a prevalence of hydrophobicity in the space deputed to bind cholesterol (Figure 5), in agreement with its marked hydrophobicity. The docking study provided a plausible binding architecture of cholesterol that was found engaging R101 with the hydroxyl group, while the polycyclic hydrophobic core was found embedded into the surrounding hydrophobic space. In more detail, hydrophobic stacking between Y97 and the $\mathrm{C}$ ring was found (Figure 5), in agreement with previous studies on cholesterol-CRAC motif interaction [32]. AOH showed a binding pose retracing the one of cholesterol (Figure 5), along with recording a very close computational score $(\mathrm{AOH}=39.693$, cholesterol $=39.697)$, that might point to its comparable capability to satisfy the space available for receiving ligands, according to previous studies [62]. In particular, the hydroxyl group in position \#7 was found engaged in a polar interaction with R101, while aromatic rings were found engaged in hydrophobic stacking with Y97. The capability of the AOH-CRAC motif interaction to persist over time was assessed by means of MD simulations. The interaction of $\mathrm{AOH}$ was found to not interfere with the overall peptide geometry, as testified by the quite stable RMSD values (root mean square deviation values), recorded along the whole simulation (Supplementary Figure S3A). This result may point to the capability of AOH to geometrically stabilize the CRAC portion of the CSD domain of caveolin-1. In addition, AOH showed a discrete reducing trend in the RMSD values along the simulation (Supplementary Figure S3B), suggesting stable interaction with the CRAC motif. Furthermore, the cluster analysis of AOH trajectory identified six geometrical clusters (RMSD cutoff $0.75 \AA$; Supplementary Figure S4), and five of them encompassed interactions with at least one of the conserved residues of the CRAC motif. This result supports the interpretation that multiple interacting modes might exist in the case of isolated peptides bearing CRAC motifs. Notably, interactions with W98 were found recurrent, implying its importance in the AOH-CRAC interaction, even though it is not included in the set of conserved residues. It is worth noticing that the polar engagement of R101 was not found in any of the calculated clusters, reflecting the minor recurrence of poses prone to form such a contact along the all simulation. Given the marked recurrence of non-polar contacts in all the clusters, these results may suggest that hydrophobic interactions have a major role in driving the interaction with the CRAC motif.

\subsection{Effect of AOH and LPS on Caveolin-1 and TLR4 in THP-1 Macrophages}

Since $\mathrm{AOH}$ seems to have the potential to substitute cholesterol in membrane proteins like caveolin-1, we decided to investigate the correlation with the transmembrane receptor TLR4. TLR4 activation is central for the LPS-induced pro-inflammatory cascade [63] and immunofluorescence confocal microscopy followed by an image analysis allowed one to localize and quantify the receptors of interests. TLR4 signal area increased significantly after incubation with LPS, as well as by incubation with $\mathrm{M} \beta \mathrm{CD}$ and $\mathrm{M} \beta \mathrm{CD} / \mathrm{AOH}$ (Figure $6 \mathrm{~A}, \mathrm{C}$ ). The signal of caveolin-1 increased after incubation with $\mathrm{AOH}$ (Figure $6 \mathrm{~A}, \mathrm{~B}, \mathrm{E}$ ) and this effect was significantly reduced by the co-incubation with $\mathrm{M} \beta \mathrm{CD}$ (Figure $6 \mathrm{~A}, \mathrm{~B})$. The signal of caveolin-1 increased upon incubation with $\mathrm{AOH}$ also in presence of LPS (Figure 6A,B). The co-localization analysis showed an increase the area TLR4/caveolin-1, in association with the $\mathrm{AOH}$ incubation. This effect was decreased by the addition of $\mathrm{M} \beta \mathrm{CD}$ (Figure $6 \mathrm{D}$ ). In LPS-stimulated cells, the effect was visible, albeit to a lesser extent, also in the presence of $M \beta C D$ and $\mathrm{M} \beta \mathrm{CD} / \mathrm{AOH}$ (Figure $6 \mathrm{~A}, \mathrm{D}$ ). All in all, these data point toward the capability of the mycotoxin $\mathrm{AOH}$ to modify the cellular localization of caveolin-1, as well as its crosstalk with TLR4.

\subsection{Effect of AOH on the PUFA and Oxylipin Profile of THP-1 Macrophages}

Since more and more evidence point toward an effect of $\mathrm{AOH}$ centered at membrane level, we investigated the effects of the mycotoxin on other key regulators of the immune response, whose activity is centered on the lipid membrane, namely hydroxyeicosatetraenoic acids (HETEs) and PUFAs. 
An untargeted approach allowed one to obtain an overview on the effects on lipid mediators, as well as on their precursors. LPS significantly decreased the concentration of arachidonic acid and oleic acid in the medium, indicating the increased enzymatic processing of these precursor molecules (Figure 7A,B). Intriguingly, this effect was also maintained also by the co-incubation LPS $+\mathrm{AOH}$, sustaining the hypothesis that when the two stimuli are applied together, the macrophages should maintain the capability to produce pro-inflammatory mediators. A tendency toward decrease was observed in parallel in all the incubation conditions that included $\mathrm{AOH}$. Moreover, the incubation with $\mathrm{M} \beta \mathrm{CD}$ alone did not elicit any effect, thus confirming on one side the data already observed with the secretome at protein level, and implying on the other that $\mathrm{AOH}$ can have a specific effect on the lipid components. As for the HETEs, AOH selectively induced the formation of 12-HETE, thus implying a possible increase of the 12-HETE-associated signals when THP-1 macrophages are incubated with the toxin. A similar trend, albeit not significant, was observed for 9-HETE (Figure 7B). Of note, 12-HETE can sustain transcription of proinflammatory mediators [64], thus adding another level to the interpretation of the biological effects of $\mathrm{AOH}$. In line, immunostaining of the cytokine MIF revealed an increase when macrophages were incubated with $\mathrm{AOH}$, thus suggesting that the mycotoxin alone could also potentially trigger some pro-inflammatory responses (Supplementary Figures S5-S7).

A

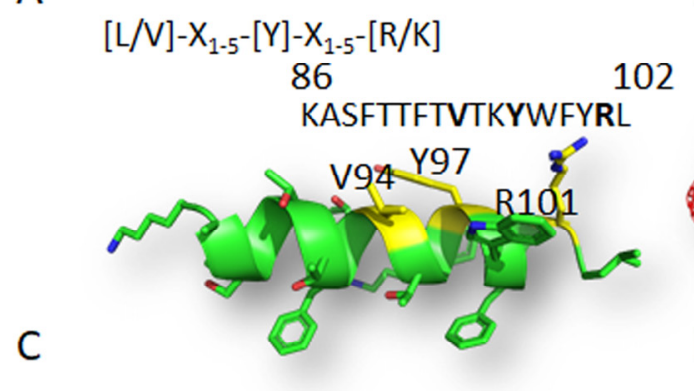

B

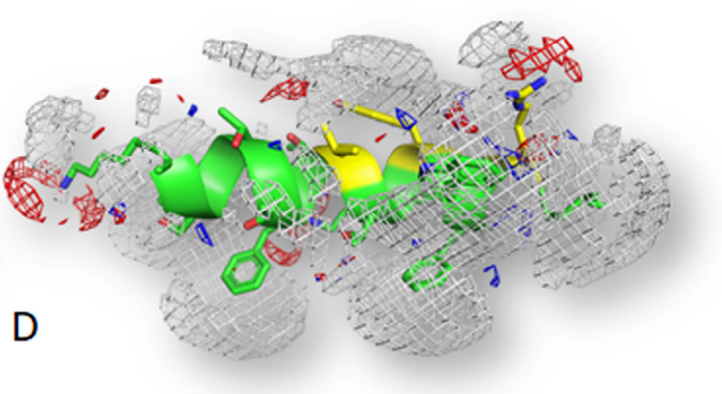

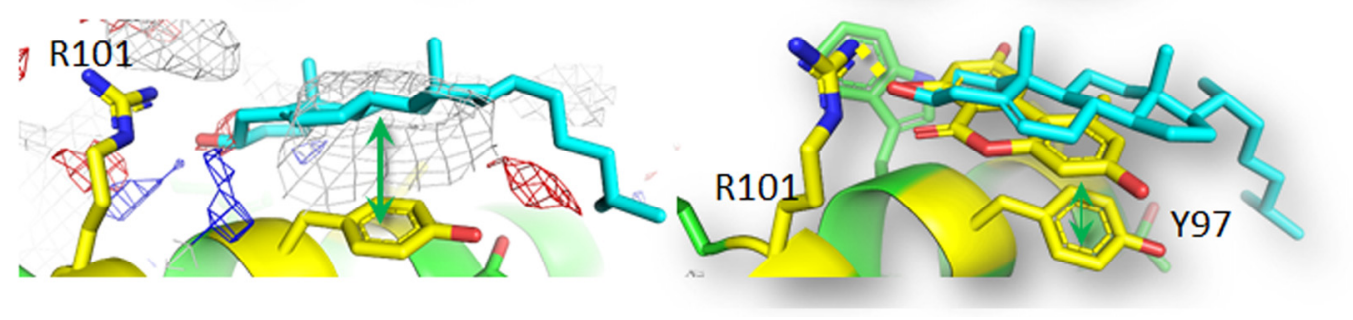

Figure 5. CRAC motif and the modeled CRAC portion of caveolin 1's CSD domain. (A) CSD sequence containing the CRAC motif is shown and the conserved residues are highlighted in bold. (B) The protein is represented in sticks and cartoon, while gray, red and blue meshes indicate regions sterically and energetically able to receive hydrophobic, $\mathrm{H}$-donor acceptor and $\mathrm{H}$-bond donor groups, respectively. (C) Calculated interaction of cholesterol (represented in cyan sticks) at the CRAC portion of caveolin 1's CSD domain. The protein is represented in sticks and cartoon, while gray, red and blue meshes indicate regions sterically and energetically able to receive hydrophobic, $\mathrm{H}$-donor acceptor and $\mathrm{H}$-bond donor groups, respectively. The green arrow indicates the formation of hydrophobic stacking, while the yellow dotted line indicates the formation of polar interaction. (D) Calculated interaction of $\mathrm{AOH}$ (represented in yellow sticks) overlapped to the calculated pose of cholesterol (represented in cyan sticks) at the CRAC portion of caveolin 1's CSD domain. The green arrow indicates the formation of hydrophobic stacking, while the yellow dotted line indicates the formation of polar interactions. 
A
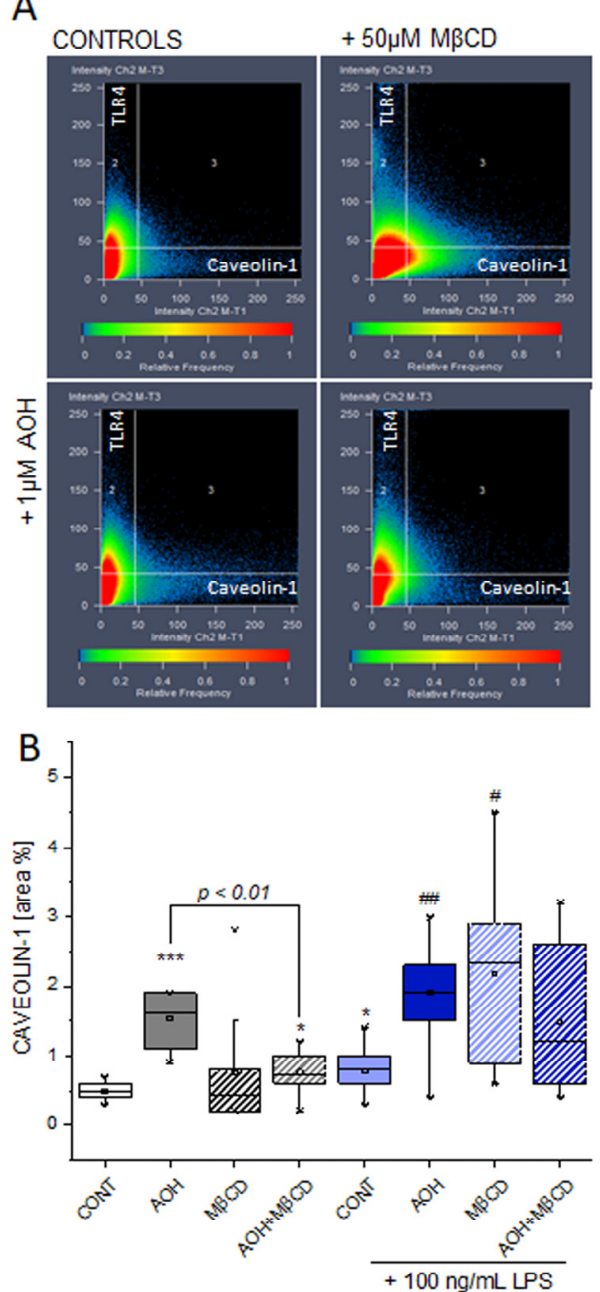

D

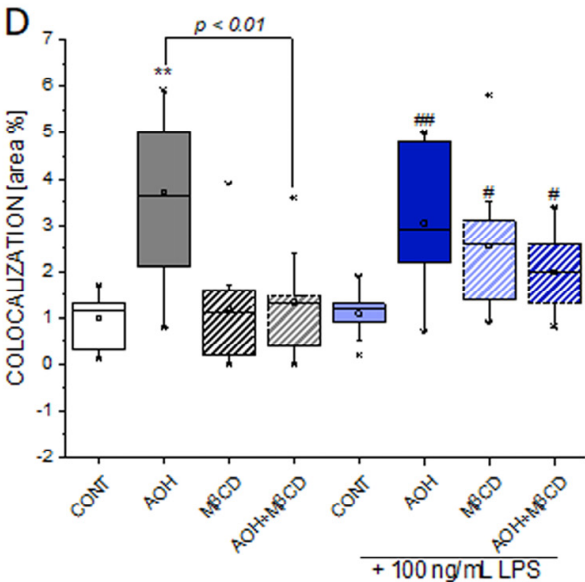

$+100 \mathrm{ng} / \mathrm{mL}$ LPS

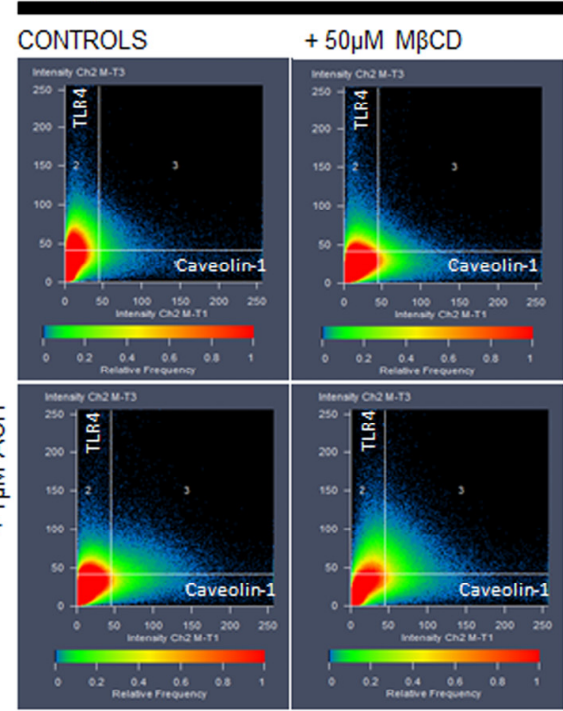

$C^{30}$

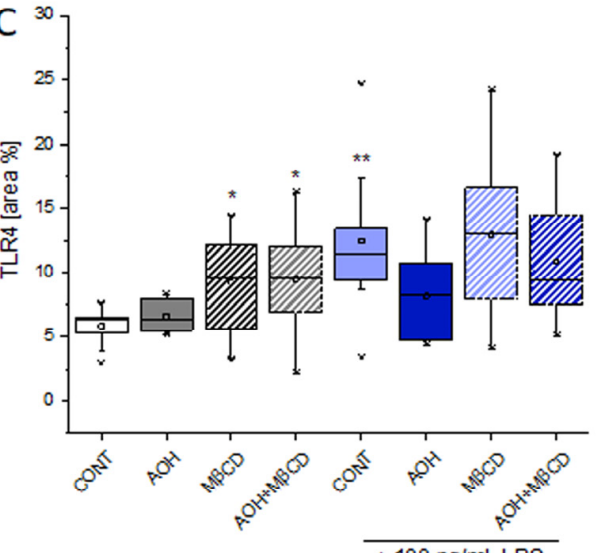

E

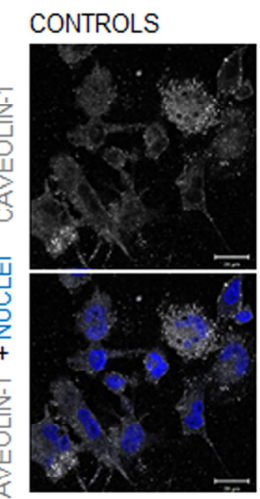

$+1 \mu \mathrm{M} \mathrm{AOH}$

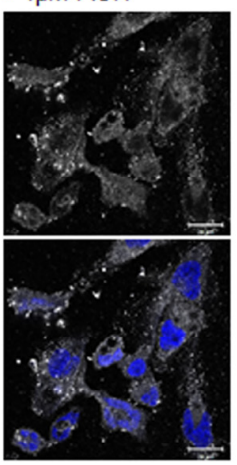

Figure 6. Influence of $\mathrm{AOH}$ on the immunolocalization of caveolin-1 and TLR4. Signal intensity and co-localization of the fluorescent signals (A). Area of caveolin-1 signal (B), TLR4 (C) and co-localization (D), after $1 \mathrm{~h}$ incubation with $1 \mu \mathrm{M} \mathrm{AOH}, 50 \mu \mathrm{M} \mathrm{M} \beta C D$, or both in presence or absence of $100 \mathrm{ng} / \mathrm{mL}$ LPS. Appearance of the immunolocalization of caveolin-1 in THP-1 macrophages in control conditions and after $1 \mathrm{~h}$ incubation with $1 \mu \mathrm{M}$ AOH (E). Scale bar, $20 \mu \mathrm{m}$. Data are mean of $\mathrm{n} \geq 8-9$ optical fields obtained from three independent experiments, ${ }^{*}(p<0.05),{ }^{* *}(p<0.01),{ }^{* * *}(p<0.001)$ and \# $(p<0.05)$, \#\# ( $p<0.01)$ indicate significant differences in comparison to controls (CONT) and CONT + LPS, respectively (Mann-Whitney test). 

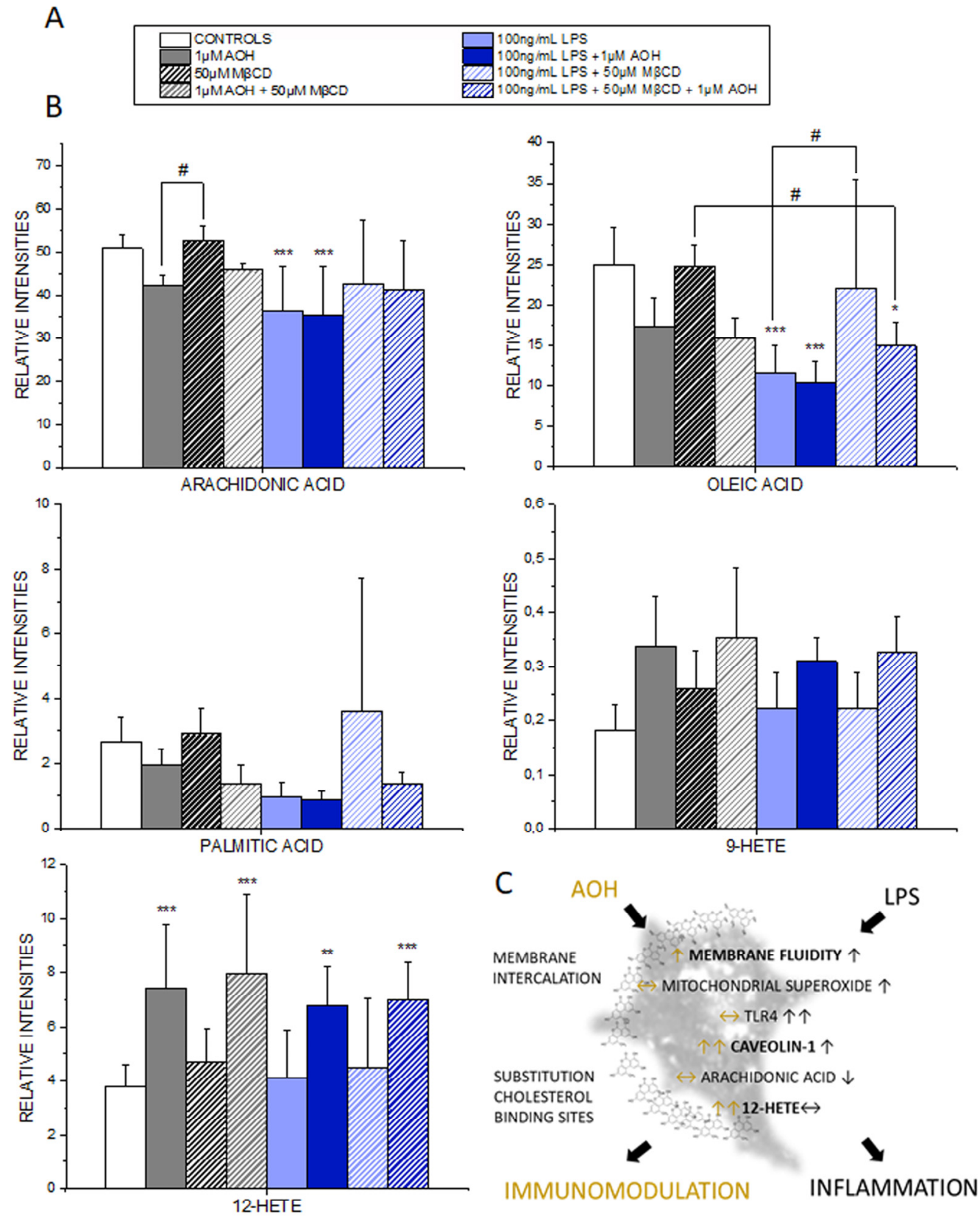

Figure 7. Influence on arachidonic, oleic and pamititc acid and on 9-and 12-HETE in the secretome of THP-1 macrophages (3 h incubation). (A) Figure color legend. (B) Data are depicting results obtained from 3 independent cell preparations. ${ }^{*}(p<0.05),{ }^{* *}(p<0.01),{ }^{* * *}(p<0.001)$ indicates significant differences in comparison to controls and \# $(p<0.05)$ indicates significant differences among the treatments (ANOVA for multiple comparisons). (C) Schematic representation of the mechanism of immunomodulatory action of $\mathrm{AOH}$.

\section{Discussion}

The description of mechanisms sustaining the immunomodulatory potential of environmental contaminants is of crucial importance; especially when exposure occurs in a domestic context, where the possibility to contain/decrease contact can be very limited, as well as risk perception. We are progressively gaining a better understanding of the toxicological potential of the exposure to molds and the subsequent relation with pathologies of the respiratory tract $[1,2,9]$. However, causal relationships and respective treatment opportunities require the elucidation of the molecular mechanisms sustaining these effects. Even though AOH was typically considered as immunosuppressive of the LPS-induced 
pro-inflammatory cascade $[3,6]$, an untargeted secretome analysis of the supernatant of macrophages incubated with LPS or LPS + AOH showed a very similar profile (Figure 1). Indeed, we obtained a comparable induction of interleukin 1 beta, the TNF receptor-associated factor 1 and tumor necrosis factor alpha-induced protein 2, as well as from C-C motif chemokine 20. In this light, when co-incubated with LPS, AOH did not seem to alter cell capability to produce pro-inflammatory signals, or at least not within a timeframe of $5 \mathrm{~h}$. This observation guided us toward the idea that $\mathrm{AOH}$ could impair signal transduction in macrophages, rather than signal generation. Pursuing this hypothesis, we compared the effect of the toxin at membrane level with that of LPS, and were able to observe, in both cases, the alteration of membrane biophysical properties (fluidity, Figure 2). However, further experiments suggested that the same result could be mediated by the activation of differential pathways. In the case of LPS, increase of membrane fluidity was parallel to the increase of the superoxide formation at mitochondrial level (Figure 3), being ROS formation a typical response of immune cells upon activation [47]. Intriguingly, $\mathrm{AOH}$ reduced also the morphological adaptation of macrophages in response to LPS (Figure 2), thus retracing the behavior of the polyphenolic flavonoid silymarin that, exactly like $\mathrm{AOH}[6]$ can block the activation of the transcription factor NF-kB as well as the LPS-induced morphological adaptation of RAW264.7 cells [65]. In our experimental conditions, we also observed that $\mathrm{AOH}$ was capable to compete with the cholesterol complexing agent $\mathrm{M} \beta \mathrm{CD}$ in the modulation of membrane biophysical properties, without the involvement of the mitochondrial activation (Figure 3). This crosstalk suggested that cholesterol containing structures like caveolae and lipid rafts [66] could be important players in the mechanism of action of $\mathrm{AOH}$. Moreover, these results supported previous work describing an increased membrane fluidity triggered by AOH ( $30 \mu \mathrm{M}, 24 \mathrm{~h}$ incubation) and a parallel alteration of the distribution of the GM1 plasma membrane raft ganglioside in RAW264.7 macrophages [5]. To sustain a potential connection with the immunomodulatory activity of $\mathrm{AOH}$, it was previously demonstrated that cholesterol depletion with $\mathrm{M} \beta C D$ and caveolin- 11 silencing abolish IL1 $\beta$-mediated MAPK-p38 signal transduction, and that tumor necrosis factor receptor-associated factor 6 (TRAF6) was essential for the activation of this pathway [67] A protein secretome analysis confirmed the potential crosstalk between $\mathrm{AOH}$ and $\mathrm{M} \beta \mathrm{CD}$. If none of the two compounds alone elicited the variation of secreted protein profiles in comparison to controls, the combination of the two significantly regulated more than 40 proteins. Depletion of membrane cholesterol via $\mathrm{M} \beta C D$ is known to modify the caveolar-proteome [68] making it plausible that combination of the two treatments ( $\mathrm{AOH}$ $+\mathrm{M} \beta C D$ ) could potentiate the biological response at this level. Among the significantly regulated proteins, several presented a link with membrane domains, like, for instance, the monocarboxylate transporter (MCT4; SLC16A3), whose expression was found to relate to that of caveolin-1 in tumor stroma [69]. Similarly, the Rho GDP-dissociation inhibitor 1 (ARHGDIA) was found to be up-regulated in the secretome by the co-incubation of $\mathrm{AOH}$ and $\mathrm{M} \beta \mathrm{CD}$. The Rho GDP-dissociation inhibitor 1 was described to localize with TNRF1 at the membrane level and to be involved in the TNF- $\alpha-$ Rho activation in a cholesterol/caveolin 1 dependent manner [70].

In line, alteration of the membrane homeostasis would impair the signal transduction in presence of pro-inflammatory stimuli. It was previously demonstrated that cholesterol loading via $\mathrm{M} \beta \mathrm{CD}$ increases the stability of caveolin-1 and its localization in the cell membrane [54]. In line with the hypothesis that $\mathrm{AOH}$ could structurally interact with the CRAC binding domain of caveolin 1 as suggested by the modelling experiments (Figure 5), incubation of THP-1 macrophages with AOH significantly increased the staining intensity of caveolin-1. The caveolin-1 response was accompanied by an increase in the co-localization with TLR4 (Figure 6A,D). These data are in accordance with previous studies describing the recruitment of TLR4 dependent from caveolin-1/FABP7 in astrocytes [71], thus providing a mechanistic insight into a possible immunomodulatory activity of the toxin also in the presence of pro-inflammatory cytokines and chemokines (as suggested in Figure 1). In accordance with the interpretation that $\mathrm{AOH}$ could compete with cholesterol at membrane level, a lipidomic profiling of the secretome was also performed. It was previously demonstrated that membrane proteins like caveolin-1 are crucial in the homeostasis of long chain fatty acids [72], and similarly, in our 
model, the processing of arachidonic acid, oleic acid and palmitic acid appeared modulated by the presence of AOH (Figure 7). Similarly, macrophages from caveolin-1 null mice were reported to exhibit elevated arachidonic acid uptake [73], and even though a postulated stabilization of caveolin-1 from $\mathrm{AOH}$ at membrane level could be associated with a gain or a loss of function, the consistency of the effect/trend on the precursors is coherent with the interpretation that $\mathrm{AOH}$ could act at this level. In agreement with the interpretation that $\mathrm{AOH}$ could stabilize the presence of caveolin-1, PUFAs show lower concentrations in presence of $\mathrm{AOH}$, in comparison to incubation conditions without mycotoxin (Figure 7) [72,74].

According to the molecular modelling experiments, $\mathrm{AOH}$ has the capability to bind to the CRAC domain of caveolin, with a scoring similar to that of cholesterol itself (Figure 5). Although topological and geometrical changes of the portion calculated cannot be ruled out in the real protein context, the results presented here were all in agreement with the capability of $\mathrm{AOH}$ to interact favorably with the CRAC portion of caveolin 1's CSD domain. On this basis, the interaction with the CSD at the CRAC locus was proposed, to mechanistically explain the possible $\mathrm{AOH}$-caveolin 1 interaction observed experimentally. A structural similarity between $\mathrm{AOH}$ and related compounds with cholesterol is at the basis of the capability of the mycotoxin to act as mycoestrogen and bind to the estrogen receptors [75]. Similarly, the stabilization of caveolin-1 at membrane level through AOH could possibly modulate inflammatory cascade via multiple mechanisms, such as, for instance: (i) altered turnover of the TLR4, (ii) altered association with TRAF1 and IL1B (iii) altered uptake of eicosanoid precursors. Considering the central role of the cell membrane in mediating the transduction of the pro-inflammatory signal, this would provide a mechanistic model to explain the immunomodulatory action of $\mathrm{AOH}$ when incubated with LPS. At the same time, we would not exclude that in some contexts the toxin could also trigger pro-inflammatory signals, thus also confirming respective literature describing the pro-inflammatory potential of $\mathrm{AOH}$ [12]. Structural similarities between $\mathrm{AOH}$ and cholesterol include the possibility of direct interaction/intercalation of the toxin in the plasma membrane, also outside caveolae. On a similar principle, structural analogy is at the bases of the capability of endocannabinoids to embed into membrane and increase their fluidity, as well as to consequently regulate lipoxygenase binding [76]. Similarly, membrane fluidity was reported to be an important modulator of the activity of the 5-lipoxygenase [20]. In line, also non-steroidal anti-inflammatory drugs-NSAIDs are able to modulate membrane fluidity, thus supporting the molecular mechanism of the drugs on the cyclooxygenase $[77,78]$. On the basis of the capability of $\mathrm{AOH}$ to increase membrane fluidity (Figure 2), this could be sufficient to support an effect on the inflammatory cascade. Accordingly, the potential effect of $\mathrm{AOH}$ on the eicosanoids production could be postulated as dependent or independent from the effect on the caveolae system. All incubation conditions, including $\mathrm{AOH}$, significantly increased the 12-HETE, and a similar tendency was observed regarding 9-HETE. In agreement we formulated the idea that the similarity between $\mathrm{AOH}$ and cholesterol could be a key to understand the immunomodulatory potential of the mycotoxin, and its mechanism of action at membrane level (Figure 7C). Cholesterol plays also an essential role in the activation of the NLRP3 inflammasome activation [79], as well as in transducing lipid peroxidation signals in macrophages [23]. In agreement, the effects of $\mathrm{AOH}$ on the immunodetection of caveolin-1 (Figure 6), and of the cytokine MIF (Supplementary Figures S5 and S7), were reduced by the cholesterol deprivation with $\mathrm{M} \beta C D$, exactly like the membrane fluidity response (Figure 2).

\section{Conclusions}

In conclusion, we described the effect of the mycotoxin AOH on several aspects of THP-1 macrophage functions. As for the interaction with the estrogen receptor and the respective effect as xenoestrogen $[75,80]$, also for the immunomodulatory potential of $\mathrm{AOH}$, the structural similarity of the toxin with endogenous molecules like cholesterol may provide the key for understanding its complex biological functions. This could be obtained either through direct interaction with the membrane, or through interaction with cholesterol containing proteins like caveolin-1 (Figure 7C). 
Supplementary Materials: The following are available online at http://www.mdpi.com/2073-4409/9/4/847/s1, Figure S1: Principal Component Analysis (PCA) of the secretome analysis Figure S2: Evaluation of the cytotoxic potential of the incubation with $\mathrm{AOH}$; Figure S3: Geometrical changes of the CRAC portion of caveolin 1's CSD domain and $\mathrm{AOH}$; Figure S4: sters identified by the cluster analysis; Figure S5: Representative images of the immunolocalization of Caveolin-1, macrophage migration inhibitory factor, toll like receptor 4 in THP-1 macrophages; Figure S6: Representative images of the immunolocalization of Caveolin-1, macrophage migration inhibitory factor, toll like receptor 4 in THP-1 macrophages; Figure S7: Effect of $1 \mathrm{~h}$ incubation with $1 \mu \mathrm{M}$ AOH and/or $50 \mu \mathrm{M} \mathrm{M} \beta \mathrm{CD}$ on the pro-inflammatory cytokine MIF.

Author Contributions: G.D.F., D.M. and C.G. planned the study. G.D.F., R.M.M., L.D., L.J., L.N. performed the experiments, G.D.F., R.M.M., L.D. and C.G. analyzed the data. C.D., D.M. and C.G. contributed reagents and financial support. G.D.F. wrote the manuscript. All the authors edited and reviewed the final version of the paper. All authors have read and agreed to the published version of the manuscript.

Funding: This work was supported by the University of Vienna and by TeachIn Parma Project.

Acknowledgments: The authors acknowledge the support of the Core Facility Multimodal Imaging of the Faculty of Chemistry and of the Joint Metabolome Facility members of the VLSI. The authors also thank the Open Access Funding by the University of Vienna. This research also benefits from the HPC (high performance computing) facility of the University of Parma, Italy.

Conflicts of Interest: The authors declare no conflict of interest. The funders had no role in the design of the study; in the collection, analyses, or interpretation of data; in the writing of the manuscript, or in the decision to publish the results.

\section{References}

1. Sahin, O.A.; Kececioglu, N.; Serdar, M.; Ozpinar, A. The association of residential mold exposure and adenotonsillar hypertrophy in children living in damp environments. Int. J. Pediatric Otorhinolaryngol. 2016, 88, 233-238. [CrossRef]

2. Castanhinha, S.; Sherburn, R.; Walker, S.; Gupta, A.; Bossley, C.J.; Buckley, J.; Ullmann, N.; Grychtol, R.; Campbell, G.; Maglione, M.; et al. Pediatric severe asthma with fungal sensitization is mediated by steroid-resistant IL-33. J. Allergy Clin. Immunol. 2015, 136, 312-322. [CrossRef]

3. Solhaug, A.; Karlsøen, L.M.; Holme, J.A.; Kristoffersen, A.B.; Eriksen, G.S. Immunomodulatory effects of individual and combined mycotoxins in the THP-1 cell line. Toxicol. Vitro (Suppl. C) 2016, 36, 120-132. [CrossRef] [PubMed]

4. Solhaug, A.; Wisbech, C.; Christoffersen, T.E.; Hult, L.O.; Lea, T.; Eriksen, G.S.; Holme, J.A. The mycotoxin alternariol induces DNA damage and modify macrophage phenotype and inflammatory responses. Toxicol. Lett. 2015, 239, 9-21. [CrossRef] [PubMed]

5. Solhaug, A.; Holme, J.A.; Haglund, K.; Dendele, B.; Sergent, O.; Pestka, J.; Lagadic-Gossmann, D.; Eriksen, G.S. Alternariol induces abnormal nuclear morphology and cell cycle arrest in murine RAW 264.7 macrophages. Toxicol. Lett. 2013, 219, 8-17. [CrossRef] [PubMed]

6. Kollarova, J.; Cenk, E.; Schmutz, C.; Marko, D. The mycotoxin alternariol suppresses lipopolysaccharide-induced inflammation in THP-1 derived macrophages targeting the NF-kappaB signalling pathway. Arch. Toxicol. 2018, 92, 3347-3358. [CrossRef] [PubMed]

7. Grover, S.; Lawrence, C.B. The Alternaria alternata Mycotoxin Alternariol Suppresses Lipopolysaccharide-Induced Inflammation. Int. J. Mol. Sci. 2017, 18, 1577. [CrossRef] [PubMed]

8. Smith, M.C.; Madec, S.; Troadec, S.; Coton, E.; Hymery, N. Effects of fusariotoxin co-exposure on THP-1 human immune cells. Cell Biol. Toxicol. 2017, 34, 191-205. [CrossRef]

9. Gabriel, M.F.; Postigo, I.; Tomaz, C.T.; Martinez, J. Alternaria alternata allergens: Markers of exposure, phylogeny and risk of fungi-induced respiratory allergy. Environ. Int. 2016, 89-90, 71-80. [CrossRef] [PubMed]

10. Puntscher, H.; Hankele, S.; Tillmann, K.; Attakpah, E.; Braun, D.; Kutt, M.L.; del Favero, G.; Aichinger, G.; Pahlke, G.; Hoger, H.; et al. Warth, First insights into Alternaria multi-toxin in vivo metabolism. Toxicol. Lett. 2018, 301, 168-178. [CrossRef]

11. Puntscher, H.; Kutt, M.L.; Skrinjar, P.; Mikula, H.; Podlech, J.; Frohlich, J.; Marko, D.; Warth, B. Tracking emerging mycotoxins in food: Development of an LC-MS/MS method for free and modified Alternaria toxins. Anal. Bioanal. Chem. 2018, 410, 4481-4494. [CrossRef] 
12. Bansal, M.; Singh, N.; Alam, S.; Pal, S.; Satyanarayana, G.N.V.; Singh, D.; Ansari, K.M. Alternariol induced proliferation in primary mouse keratinocytes and inflammation in mouse skin is regulated via PGE2/EP2/cAMP/p-CREB signaling pathway. Toxicology 2019, 412, 79-88. [CrossRef] [PubMed]

13. Solhaug, A.; Vines, L.L.; Ivanova, L.; Spilsberg, B.; Holme, J.A.; Pestka, J.; Collins, A.; Eriksen, G.S. Mechanisms involved in alternariol-induced cell cycle arrest. Mutat. Res. 2012, 738-739, 1-11. [CrossRef] [PubMed]

14. Solhaug, A.; Torgersen, M.L.; Holme, J.A.; Lagadic-Gossmann, D.; Eriksen, G.S. Autophagy and senescence, stress responses induced by the DNA-damaging mycotoxin alternariol. Toxicology 2014, 326, 119-129. [CrossRef] [PubMed]

15. Schmutz, C.; Cenk, E.; Marko, D. The Alternaria Mycotoxin Alternariol Triggers the Immune Response of IL-1beta-stimulated, Differentiated Caco-2 Cells. Mol. Nutr. Food Res. 2019, 63, e1900341. [CrossRef] [PubMed]

16. Köberlin, M.S.; Heinz, L.X.; Superti-Furga, G. Functional crosstalk between membrane lipids and TLR biology. Curr. Opin. Cell Biol. 2016, 39, 28-36. [CrossRef] [PubMed]

17. Hoop, C.L.; Sivanandam, V.N.; Kodali, R.; Srnec, M.N.; van der Wel, P.C. Structural characterization of the caveolin scaffolding domain in association with cholesterol-rich membranes. Biochemistry 2012, 51, 90-99. [CrossRef]

18. Agache, I.; Annesi-Maesano, I.; Bonertz, A.; Branca, F.; Cant, A.; Fras, Z.; Ingenrieth, F.; Namazova-Baranova, L.; Odemyr, M.; Spanevello, A.; et al. Prioritising research challenges and funding for allergy and asthma and the need for translational research-The European Strategic Forum on Allergic Diseases. Allergy 2019, 74, 2064-2076. [CrossRef]

19. Kandasamy, P.; Numata, M.; Berry, K.Z.; Fickes, R.; Leslie, C.C.; Murphy, R.C.; Voelker, D.R. Structural analogs of pulmonary surfactant phosphatidylglycerol inhibit toll-like receptor 2 and 4 signaling. J. Lipid Res. 2016, 57, 993-1005. [CrossRef]

20. Pande, A.H.; Qin, S.; Tatulian, S.A. Membrane fluidity is a key modulator of membrane binding, insertion, and activity of 5-lipoxygenase. Biophys. J. 2005, 88, 4084-4094. [CrossRef]

21. De la Haba, C.; Morros, A.; Martinez, P.; Palacio, J.R. LPS-Induced Macrophage Activation and Plasma Membrane Fluidity Changes are Inhibited Under Oxidative Stress. J. Membr. Biol. 2016, 249, 789-800. [CrossRef] [PubMed]

22. De la Haba, C.; Palacio, J.R.; Martinez, P.; Morros, A. Effect of oxidative stress on plasma membrane fluidity of THP-1 induced macrophages. Biochim. Biophys. Acta 2013, 1828, 357-364. [CrossRef] [PubMed]

23. Del Favero, G.; Hohenbichler, J.; Mayer, R.M.; Rychlik, M.; Marko, D. Mycotoxin Altertoxin II Induces Lipid Peroxidation Connecting Mitochondrial Stress Response to NF-kappaB Inhibition in THP-1 Macrophages. Chem. Res. Toxicol. 2020, 33, 492-504. [CrossRef] [PubMed]

24. Chanput, W.; Mes, J.J.; Wichers, H.J. THP-1 cell line: An in vitro cell model for immune modulation approach. Int. Immunopharmacol. 2014, 23, 37-45. [CrossRef] [PubMed]

25. Mayer, R.L.; Schwarzmeier, J.D.; Gerner, M.C.; Bileck, A.; Mader, J.C.; Meier-Menches, S.M.; Gerner, S.M.; Schmetterer, K.G.; Pukrop, T.; Reichle, A.; et al. Proteomics and metabolomics identify molecular mechanisms of aging potentially predisposing for chronic lymphocytic leukemia. Mol. Cell. Proteom. MCP 2018, 17, 290-303. [CrossRef]

26. Jarolim, K.; del Favero, G.; Pahlke, G.; Dostal, V.; Zimmermann, K.; Heiss, E.; Ellmer, D.; Stark, T.D.; Hofmann, T.; Marko, D. Activation of the Nrf2-ARE pathway by the Alternaria alternata mycotoxins altertoxin I and II. Arch. Toxicol. 2017, 91, 203-216. [CrossRef] [PubMed]

27. Tyanova, S.; Temu, T.; Cox, J. The MaxQuant computational platform for mass spectrometry-based shotgun proteomics. Nat. Protoc. 2016, 11, 2301-2319. [CrossRef]

28. Tyanova, S.; Temu, T.; Carlson, A.; Sinitcyn, P.; Mann, M.; Cox, J. Visualization of LC-MS/MS proteomics data in MaxQuant. Proteomics 2015, 15, 1453-1456. [CrossRef]

29. Cox, J.; Neuhauser, N.; Michalski, A.; Scheltema, R.A.; Olsen, J.V.; Mann, M. Andromeda: A peptide search engine integrated into the MaxQuant environment. J. Proteome Res. 2011, 10, 1794-1805. [CrossRef]

30. Cox, J.; Mann, M. MaxQuant enables high peptide identification rates, individualized p.p.b.-range mass accuracies and proteome-wide protein quantification. Nat. Biotechnol. 2008, 26, 1367-1372. [CrossRef]

31. Cox, J.; Mann, M. 1D and 2D annotation enrichment: A statistical method integrating quantitative proteomics with complementary high-throughput data. BMC Bioinform. 2012, 13, S12. [CrossRef] [PubMed] 
32. Fantini, J.; Barrantes, F.J. How cholesterol interacts with membrane proteins: An exploration of cholesterol-binding sites including CRAC, CARC, and tilted domains. Front. Physiol. 2013, 4, 31. [CrossRef] [PubMed]

33. Baier, C.J.; Fantini, J.; Barrantes, F.J. Disclosure of cholesterol recognition motifs in transmembrane domains of the human nicotinic acetylcholine receptor. Sci. Rep. 2011, 1, 69. [CrossRef] [PubMed]

34. Le Lan, C.; Gallay, J.; Vincent, M.; Neumann, J.M.; de Foresta, B.; Jamin, N. Structural and dynamic properties of juxta-membrane segments of caveolin-1 and caveolin-2 at the membrane interface. Eur. Biophys. J. EBJ 2010, 39, 307-325. [CrossRef]

35. Epand, R.M. Proteins and cholesterol-rich domains. Biochim. Biophys. Acta 2008, 1778, 1576-1582. [CrossRef]

36. Baroni, M.; Cruciani, G.; Sciabola, S.; Perruccio, F.; Mason, J.S. A common reference framework for analyzing/comparing proteins and ligands. Fingerprints for Ligands and Proteins (FLAP): Theory and application. J. Chem. Inf. Model. 2007, 47, 279-294. [CrossRef]

37. Jones, G.; Willett, P.; Glen, R.C.; Leach, A.R.; Taylor, R. Development and validation of a genetic algorithm for flexible docking. J. Mol. Biol. 1997, 267, 727-748. [CrossRef]

38. Dellafiora, L.; Galaverna, G.; Dall'Asta, C. Mechanisms of Fumonisin B1 Toxicity: A Computational Perspective beyond the Ceramide Synthases Inhibition. Chem. Res. Toxicol. 2018, 31, 1203-1212. [CrossRef]

39. Abraham, M.J.; Murtola, T.; Schulz, R.; Páll, S.; Smith, J.C.; Hess, B.; Lindahl, E. GROMACS: High performance molecular simulations through multi-level parallelism from laptops to supercomputers. SoftwareX 2015, 1-2, 19-25. [CrossRef]

40. Best, R.B.; Zhu, X.; Shim, J.; Lopes, P.E.; Mittal, J.; Feig, M.; Mackerell, A.D., Jr. Optimization of the additive CHARMM all-atom protein force field targeting improved sampling of the backbone phi, psi and side-chain chi(1) and chi(2) dihedral angles. J. Chem. Theory Comput. 2012, 8, 3257-3273. [CrossRef]

41. Dellafiora, L.; Galaverna, G.; Cruciani, G.; Dall'Asta, C. A computational study toward the "personalized" activity of alternariol - Does it matter for safe food at individual level? Food Chem. Toxicol. 2019, 130, $199-206$. [CrossRef] [PubMed]

42. Kanzler, H.; Barrat, F.J.; Hessel, E.M.; Coffman, R.L. Therapeutic targeting of innate immunity with Toll-like receptor agonists and antagonists. Nat. Med. 2007, 13, 552. [CrossRef] [PubMed]

43. Lopez, C.A.; de Vries, A.H.; Marrink, S.J. Computational microscopy of cyclodextrin mediated cholesterol extraction from lipid model membranes. Sci. Rep. 2013, 3, 2071. [CrossRef] [PubMed]

44. Shimizu, M.; Ogura, K.; Mizoguchi, I.; Chiba, Y.; Higuchi, K.; Ohtsuka, H.; Mizuguchi, J.; Yoshimoto, T. IL-27 promotes nitric oxide production induced by LPS through STAT1, NF-kappaB and MAPKs. Immunobiology 2013, 218, 628-634. [CrossRef]

45. Yusupov, M.; Wende, K.; Kupsch, S.; Neyts, E.C.; Reuter, S.; Bogaerts, A. Effect of head group and lipid tail oxidation in the cell membrane revealed through integrated simulations and experiments. Sci. Rep. 2017, 7, 5761. [CrossRef]

46. Morgan, M.J.; Liu, Z.-G. Crosstalk of reactive oxygen species and NF-kB signaling. Cell Res. 2011, 21, $103-115$. [CrossRef]

47. Gerner, M.C.; Niederstaetter, L.; Ziegler, L.; Bileck, A.; Slany, A.; Janker, L.; Schmidt, R.L.J.; Gerner, C.; del Favero, G.; Schmetterer, K.G. Proteome Analysis Reveals Distinct Mitochondrial Functions Linked to Interferon Response Patterns in Activated CD4+ and CD8+ T Cells. Front. Pharmacol. 2019, 10, 727. [CrossRef]

48. Attwood, P.V.; Muimo, R. The actions of NME1/NDPK-A and NME2/NDPK-B as protein kinases. Lab. Invest. 2018, 98, 283-290.

49. Boulter, E.; Garcia-Mata, R.; Guilluy, C.; Dubash, A.; Rossi, G.; Brennwald, P.J.; Burridge, K. Regulation of Rho GTPase crosstalk, degradation and activity by RhoGDI1. Nat. Cell Biol. 2010, 12, 477-483. [CrossRef]

50. Bozza, W.P.; Zhang, Y.; Hallett, K.; Rosado, L.A.R.; Zhang, B. RhoGDI deficiency induces constitutive activation of Rho GTPases and COX-2 pathways in association with breast cancer progression. Oncotarget 2015, 6, 32723-32736. [CrossRef]

51. Otto, A.; Müller, C.; Huff, T.; Hannappel, E. Chemotherapeutic drugs change actin skeleton organization and the expression of beta-thymosins in human breast cancer cells. J. Cancer Res. Clin. Oncol. 2002, 128, 247-256. 
52. Vlijm, R.; Li, X.; Panic, M.; Rüthnick, D.; Hata, S.; Herrmannsdörfer, F.; Kuner, T.; Heilemann, M.; Engelhardt, J.; Hell, S.W.; et al. STED nanoscopy of the centrosome linker reveals a CEP68-organized, periodic rootletin network anchored to a C-Nap1 ring at centrioles. Proc. Natl. Acad. Sci. USA 2018, 115, E2246-E2253. [CrossRef]

53. Baietti, M.F.; Zhang, Z.; Mortier, E.; Melchior, A.; Degeest, G.; Geeraerts, A.; Ivarsson, Y.; Depoortere, F.; Coomans, C.; Vermeiren, E.; et al. Syndecan-syntenin-ALIX regulates the biogenesis of exosomes. Nat. Cell Biol. 2012, 14, 677-685. [CrossRef]

54. Frank, P.G.; Marcel, Y.L.; Connelly, M.A.; Lublin, D.M.; Franklin, V.; Williams, D.L.; Lisanti, M.P. Stabilization of caveolin-1 by cellular cholesterol and scavenger receptor class B type I. Biochemistry 2002, 41, 11931-11940. [CrossRef] [PubMed]

55. Jiao, H.; Zhang, Y.; Yan, Z.; Wang, Z.G.; Liu, G.; Minshall, R.D.; Malik, A.B.; Hu, G. Caveolin-1 Tyr14 phosphorylation induces interaction with TLR4 in endothelial cells and mediates MyD88-dependent signaling and sepsis-induced lung inflammation. J. Immunol. 1950 2013, 191, 6191-6199. [CrossRef] [PubMed]

56. Kim, Y.J.; Hirabayashi, Y. Caveolin-1 prevents palmitate-induced NF-kappaB signaling by inhibiting GPRC5B-phosphorylation. Biochem. Biophys. Res. Commun. 2018, 503, 2673-2677. [CrossRef] [PubMed]

57. Lee, C.Y.; Lai, T.Y.; Tsai, M.K.; Chang, Y.C.; Ho, Y.H.; Yu, I.S.; Yeh, T.W.; Chou, C.C.; Lin, Y.S.; Lawrence, T.; et al. The ubiquitin ligase ZNRF1 promotes caveolin-1 ubiquitination and degradation to modulate inflammation. Nat. Commun. 2017, 8, 15502. [CrossRef]

58. De Almeida, C.J.G. Caveolin-1 and Caveolin-2 Can Be Antagonistic Partners in Inflammation and Beyond. Front. Immunol. 2017, 8, 1530. [CrossRef]

59. Yeh, Y.C.; Ling, J.Y.; Chen, W.C.; Lin, H.H.; Tang, M.J. Mechanotransduction of matrix stiffness in regulation of focal adhesion size and number: Reciprocal regulation of caveolin-1 and beta1 integrin. Sci. Rep. 2017, 7, 15008. [CrossRef]

60. Wilde, L.; Roche, M.; Domingo-Vidal, M.; Tanson, K.; Philp, N.; Curry, J.; Martinez-Outschoorn, U. Metabolic coupling and the Reverse Warburg Effect in cancer: Implications for novel biomarker and anticancer agent development. Semin. Oncol. 2017, 44, 198-203. [CrossRef]

61. Busija, A.R.; Patel, H.H.; Insel, P.A. Caveolins and cavins in the trafficking, maturation, and degradation of caveolae: Implications for cell physiology. Am. J. Physiol. Cell Physiol. 2017, 312, C459-C477. [CrossRef] [PubMed]

62. Dellafiora, L.; Galaverna, G.; Dall'Asta, C.; Cozzini, P. Hazard identification of cis/trans-zearalenone through the looking-glass. Food Chem. Toxicol. 2015, 86, 65-71. [CrossRef] [PubMed]

63. Xu, Y.; Tao, X.; Shen, B.; Horng, T.; Medzhitov, R.; Manley, J.L.; Tong, L. Structural basis for signal transduction by the Toll/interleukin-1 receptor domains. Nature 2000, 408, 111-115. [CrossRef] [PubMed]

64. Kain, V.; Halade, G.V. Immune responsive resolvin D1 programs peritoneal macrophages and cardiac fibroblast phenotypes in diversified metabolic microenvironment. J. Cell. Physiol. 2018, 234, 3910-3920. [CrossRef] [PubMed]

65. Kim, E.J.; Lee, M.Y.; Jeon, Y.J. Silymarin Inhibits Morphological Changes in LPS-Stimulated Macrophages by Blocking NF-kappaB Pathway. Korean J. Physiol. Pharmacol. 2015, 19, 211-218. [CrossRef] [PubMed]

66. Graziani, A.; Bricko, V.; Carmignani, M.; Graier, W.F.; Groschner, K. Cholesterol- and caveolin-rich membrane domains are essential for phospholipase A2-dependent EDHF formation. Cardiovasc. Res. 2004, 64, $234-242$. [CrossRef]

67. Jagielska, J.; Kapopara, P.R.; Salguero, G.; Scherr, M.; Schutt, H.; Grote, K.; Schieffer, B.; Bavendiek, U. Interleukin-1 assembles a proangiogenic signaling module consisting of caveolin-1, tumor necrosis factor receptor-associated factor 6, p38-mitogen-activated protein kinase (MAPK), and MAPK-activated protein kinase 2 in endothelial cells. Arterioscler. Thromb. Vasc. Biol. 2012, 32, 1280-1288. [CrossRef]

68. Zheng, Y.Z.; Boscher, C.; Inder, K.L.; Fairbank, M.; Loo, D.; Hill, M.M.; Nabi, I.R.; Foster, L.J. Differential impact of caveolae and caveolin-1 scaffolds on the membrane raft proteome. Mol. Cell. Proteomics 2011, 10, M110.007146. [CrossRef]

69. Martins, D.; Beca, F.F.; Sousa, B.; Baltazar, F.; Paredes, J.; Schmitt, F. Loss of caveolin-1 and gain of MCT4 expression in the tumor stroma: Key events in the progression from an in situ to an invasive breast carcinoma. Cell Cycle 2013, 12, 2684-2890. [CrossRef] 
70. Hunter, I.; Nixon, G.F. Spatial compartmentalization of tumor necrosis factor (TNF) receptor 1-dependent signaling pathways in human airway smooth muscle cells. Lipid rafts are essential for TNF-alpha-mediated activation of RhoA but dispensable for the activation of the NF-kappaB and MAPK pathways. J. Biol. Chem. 2006, 281, 34705-34715. [PubMed]

71. Kagawa, Y.; Yasumoto, Y.; Sharifi, K.; Ebrahimi, M.; Islam, A.; Miyazaki, H.; Yamamoto, Y.; Sawada, T.; Kishi, H.; Kobayashi, S.; et al. Fatty acid-binding protein 7 regulates function of caveolae in astrocytes through expression of caveolin-1. Glia 2015, 63, 780-794. [CrossRef] [PubMed]

72. Pohl, J.; Ring, A.; Stremmel, W. Uptake of long-chain fatty acids in HepG2 cells involves caveolae: Analysis of a novel pathway. J. Lipid Res. 2002, 43, 1390-1399. [CrossRef]

73. Astudillo, A.M.; Perez-Chacon, G.; Meana, C.; Balgoma, D.; Pol, A.; del Pozo, M.A.; Balboa, M.A.; Balsinde, J. Altered arachidonate distribution in macrophages from caveolin-1 null mice leading to reduced eicosanoid synthesis. J. Biol. Chem. 2011, 286, 35299-35307. [CrossRef] [PubMed]

74. Cai, Q.; Guo, L.; Gao, H.; Li, X.-A. Caveolar Fatty Acids and Acylation of Caveolin-1. PLoS ONE 2013, 8, e60884. [CrossRef]

75. Dellafiora, L.; Warth, B.; Schmidt, V.; del Favero, G.; Mikula, H.; Frohlich, J.; Marko, D. An integrated in silico/in vitro approach to assess the xenoestrogenic potential of Alternaria mycotoxins and metabolites. Food Chem. 2018, 248, 253-261. [CrossRef] [PubMed]

76. Dainese, E.; Sabatucci, A.; Angelucci, C.B.; Barsacchi, D.; Chiarini, M.; Maccarrone, M. Impact of embedded endocannabinoids and their oxygenation by lipoxygenase on membrane properties. ACS Chem. Neurosci. 2012, 3, 386-392. [CrossRef]

77. Pereira-Leite, C.; Nunes, C.; Reis, S. Interaction of nonsteroidal anti-inflammatory drugs with membranes: In vitro assessment and relevance for their biological actions. Prog. Lipid Res. 2013, 52, 571-584. [CrossRef]

78. Sousa, C.; Nunes, C.; Lucio, M.; Ferreira, H.; Lima, J.L.; Tavares, J.; Cordeiro-da-Silva, A.; Reis, S. Effect of nonsteroidal anti-inflammatory drugs on the cellular membrane fluidity. J. Pharm. Sci. 2008, 97, 3195-3206. [CrossRef]

79. De la Roche, M.; Hamilton, C.; Mortensen, R.; Jeyaprakash, A.A.; Ghosh, S.; Anand, P.K. Trafficking of cholesterol to the ER is required for NLRP3 inflammasome activation. J. Cell Biol. 2018, 217, 3560-3576. [CrossRef]

80. Lehmann, L.; Wagner, J.; Metzler, M. Estrogenic and clastogenic potential of the mycotoxin alternariol in cultured mammalian cells. Food Chem. Toxicol. 2006, 44, 398-408. [CrossRef] 